\title{
Recent Developments in Polyene Cyclizations and Their Applications in Natural Product Synthesis
}

\author{
Anthony G. M. Barrett* (1) \\ Tsz-Kan Ma \\ Thomas Mies
}

Department of Chemistry, Imperial College London, Molecular Sciences Research Hub, White City Campus, Wood Lane, London, W12 0BZ, UK

agmb@ic.ac.uk

Published as part of the 50 Years SYNTHESIS - Golden Anniversary Issue
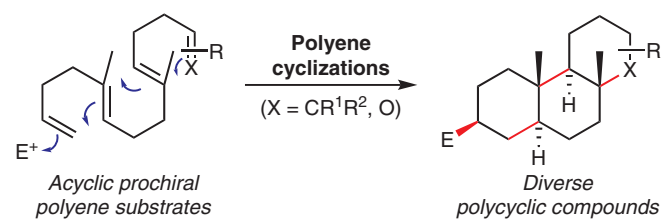

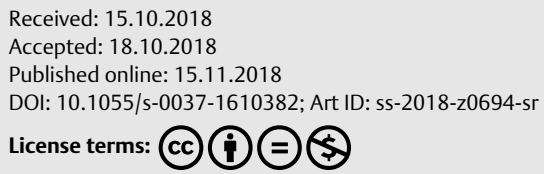

Abstract Cascade polyene cyclization reactions are highly efficient and elegant bioinspired transformations that involve simultaneous multiple bond constructions to rapidly generate complex polycyclic molecules. This review summarizes the most prominent work on a variety of cationic and radical cascade cyclizations and their applications in natural product synthesis published between 2014 and 2018.

1 Introduction

2 Cationic Polyene Cyclizations

2.1 Lewis Acid Mediated Polyene Cyclizations

2.2 Brønsted Acid Mediated Polyene Cyclizations

2.3 Halogen Electrophile Initiated Polyene Cyclizations

2.4 Sulfur Electrophile Initiated Polyene Cyclizations

2.5 Transition-Metal-Mediated Cationic Polyene Cyclizations

3 Radical Polyene Cyclizations

3.1 Transition-Metal-Mediated Radical Polyene Cyclizations

3.2 Photocatalyst-Mediated Polyene Cyclizations

4 Origin of Stereocontrol in Polyene Cyclizations

5 Conclusion

Key words polyene cyclization, cascade reaction, carbon-carbon bond formation, natural products, total synthesis

\section{Introduction}

Biomimetic strategies are powerful methods in natural product synthesis since they can provide concise methods for the elaboration of structurally complex molecules from significantly simpler precursors. Polyene cyclizations are recognized as unique and efficient ways to build structural complexity from acyclic molecules via concerted and stereocontrolled C-C bond formations. In 1955, Stork and Eschenmoser independently published a hypothesis rationalizing the stereoelectronic aspects that underpin the stereochemical outcomes of polyene cyclizations, which immediately encouraged further studies on these types of
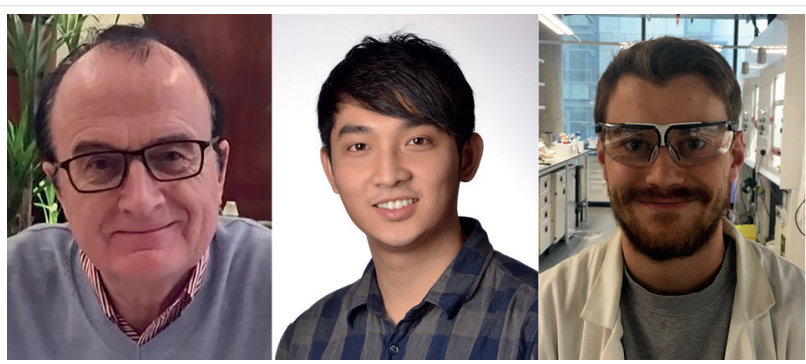

Anthony G. M. Barrett received his Ph.D. at Imperial College London with Professor Sir Derek H. R. Barton. He has held faculty positions at Imperial College London, Northwestern University, and Colorado State University. He is currently Glaxo Professor of Organic Chemistry and the Sir Derek Barton Professor of Synthesis at Imperial College London.

Tsz-Kan Ma received his M.Sci. in Chemistry with Medicinal Chemistry at Imperial College, where he is also undertaking his Ph.D. studies.

Thomas Mies received his B.Sc. degree in Chemistry and Biochemistry from the Ludwig Maximilian University of Munich. After graduating from Imperial College (IC) with an M.Res. degree in Chemical Biology, he's now undertaking his Ph.D. at IC.

transformations. ${ }^{1}$ In 1968 and 1975, pioneering research on the biomimetic syntheses of steroids was reported by Johnson $^{2}$ and van Tamelen, ${ }^{3}$ both of whom demonstrated the profound synthetic power of polyene cyclizations in natural product total synthesis.

Inspired by these revolutionary investigations into the use of polyene cyclizations in organic synthesis, considerable advancements have been achieved in the past several decades to improve the efficiency of this biomimetic process, develop novel creative variants of the cyclization processes, as well as invent novel chiral reagents and catalysts to induce highly enantioselective and regioselective cyclizations, with comparable selectivity to the enzyme-controlled cyclizations in nature. ${ }^{4}$ Snyder, Gagné, Anderson, and Sarlah previously reviewed this topic from 2000 to 2016. ${ }^{4}$ The aim of this review is to provide an updated over- 
view of cascade polyene cyclizations and their applications toward natural product synthesis from 2014 to 2018 . These cyclization processes are first divided mechanistically into cationic and radical pathways and are further subcategorized according to the mode of activation.

\section{Cationic Polyene Cyclizations}

\subsection{Lewis Acid Mediated Polyene Cyclizations}

In 2014, Li and co-workers reported the synthesis of antitumor and anti-inflammatory natural products triptolide (4), triptonide (5), and related analogues which utilized a series of metal-mediated reactions (Scheme 1). ${ }^{5}$ Functionalization of carboxylic acid $\mathbf{1}$ provided alkyne $\mathbf{2}$. The subsequent key step involved an indium bromide mediated polyene cyclization, which was originally developed by Corey and co-workers, ${ }^{6}$ to furnish the trans-fused ring framework 3 (75\%).
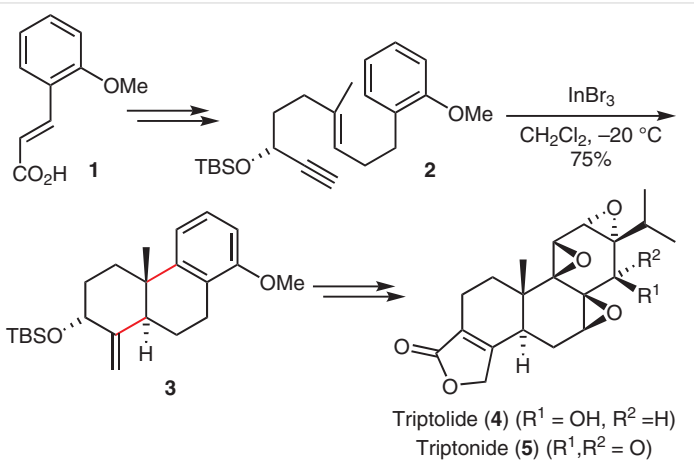

Scheme 1 Synthesis of triptolide and triptonide
The Barrett group has applied a dual biomimetic approach to the synthesis of $(+)$-hongoquercin $B(\mathbf{9})$ by successive polyketide and polyene cascade cyclizations (Scheme 2). ${ }^{7}$ Cyclo-aromatization of $\beta, \delta$-diketo-dioxinone $\mathbf{6}$ and subsequent enantioselective epoxidation provided resorcylate 7. Reaction of resorcylate $\mathbf{7}$ with iron(III) chloride hexahydrate catalyzed polyene cyclization to provide the meroterpenoid 8 (56\%, 92\% ee) as a single diastereomer and demonstrated that the single epoxide stereocenter controlled the resulting five stereocenters formed during this transformation.

In the synthesis of atropisomeric indoloterpenoid natural product (+)-dixiamycin B (12), the Baran group utilized a boron trifluoride-diethyl ether complex mediated cyclization of epoxide $\mathbf{1 0}$ into alcohol $\mathbf{1 1}$ as the key step to furnish the pentacyclic core (Scheme 3$){ }^{8}$ It was observed that the $\mathrm{N}$-protection with $\mathrm{Boc}_{2} \mathrm{O}$ was essential in order to suppress the formation of undesired isomers during polyene cyclization, thereby enhancing the yield of alcohol $\mathbf{1 1 .}$

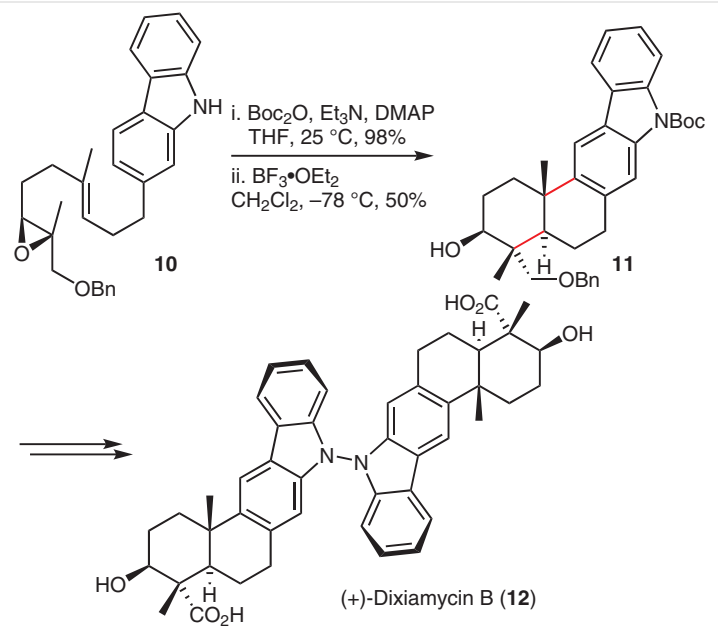

Scheme 3 Synthesis of (+)-dixiamycin B

While polyene cyclization reactions are often used in the synthesis of fused polycyclic ring systems, their use in the construction of bridged polycyclic ring systems was only recently, in 2015, explored by Nakamura and co-workers (Scheme 4). ${ }^{9}$ Exposure of epoxyallylsilane 13 to diethylaluminum chloride resulted in polyene cyclization via carbocation intermediates $\mathbf{1 4}$ and $\mathbf{1 5}$ to produce bridged tricyclic compound 16 (72\%) after hydrolysis. Tetracyclic product 18 (37\%) was also obtained under the same conditions from epoxyallylsilane $\mathbf{1 7 .}$

A systematic study of using functionalized unsaturated oxiranes in Lewis acid mediated polyene cyclization was published by Corey and co-workers, providing valuable insight into the electronic effects of neighboring substituents in epoxide initiated cationic $\pi$-cyclizations (Scheme 5). ${ }^{10}$

Scheme 2 Synthesis of (+)-hongoquercin B 
<smiles>C=C[C@@]1(C)O[C@H]2CCC(I)=CC[C@@]2(C)CCCC1=C(C)OCC</smiles>
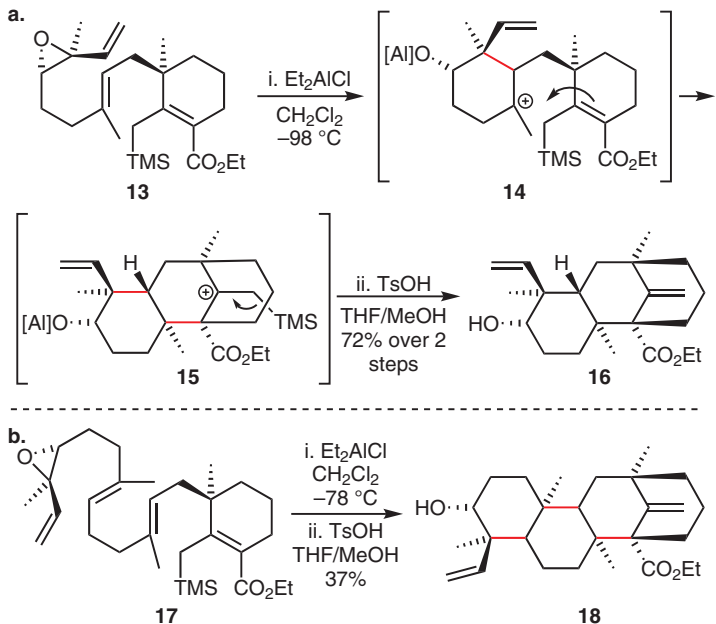

18

Scheme 4 Syntheses of bridged tri- and tetracyclic compounds

Enantiomerically enriched epoxy alcohol $\mathbf{2 1}$ was efficiently prepared from alcohol $\mathbf{1 9}$ via enantioselective KatsukiSharpless epoxidation to give epoxide $\mathbf{2 0}$ ( $86 \%, 90 \%$ ee). Further derivatization of epoxy alcohol $\mathbf{2 1}$ gave functionalized oxiranes 22a-26a. It was found that aldehyde 22a (Scheme $5 b$, entry 1 ) and ester 23a (Scheme 5b, entry 2 ) were unreactive when exposed to tin(IV) chloride. It is postulated that chelation of tin(IV) chloride by the epoxide and carbonyl groups did not facilitate cyclization, but prevent it from occurring as the carbonyl group becomes electron deficient, inhibiting the heterolysis of the oxirane $\alpha-\mathrm{C}-\mathrm{O}$ bond. In contrast, reaction of methoxime 24a (Scheme 5b, entry 3) with tin(IV) chloride resulted in polyene cyclization to give tricyclic product 24b (95\%), which could be explained by the electron-donating nature of the methoxy group, favoring the heterolytic fission of the oxirane $\alpha-\mathrm{C}-\mathrm{O}$ bond. Vinyloxirane 25a (Scheme 5b, entry 4) was also smoothly cyclized to provide the tricyclic product $\mathbf{2 5 b}$ (84\%) on reaction with tin(IV) chloride. This result demonstrates that substitution on the epoxide may facilitate the Lewis acid activation of the epoxide moiety; the resulting polyene cyclization is assisted by the $\pi$-electron-donating nature of its substituent. Furthermore, it was found that conversion of epoxide alcohol 21 into alkoxytrichlorostannane complex 26a (Scheme 5b, entry 5) also facilitated epoxide activation by covalently attaching a Lewis acid to the substrate, thereby leading to tricyclic diol 26b (82\%) on destannylative work-up.

Celastroid natural products have a range of promising biological activities and are being studied in clinical trials. Seigel and co-workers reported the first total synthesis of celastrol (29) which utilized polyene cyclization as the key step to elaborate the pentacyclic core (Scheme 6). ${ }^{11}$ Iron(III) chloride catalyzed polyene cyclization of allylic alcohol $\mathbf{2 7}$ produced pentacyclic alkene $\mathbf{2 8}(38 \%)$ on a gram scale. The use of tin(IV) chloride for this cyclization was less efficient, a.
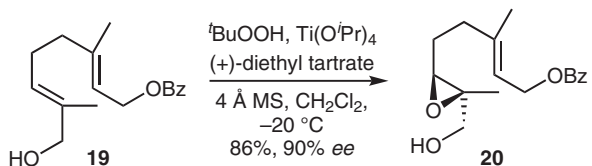

BnB

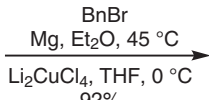

$92 \%$

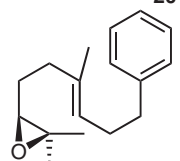

HO- 21

b.
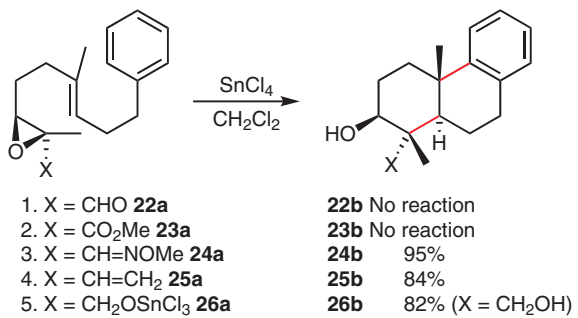

Scheme 5 Synthesis of an epoxy alcohol and derivatization into different substrates for polyene cyclization reactions
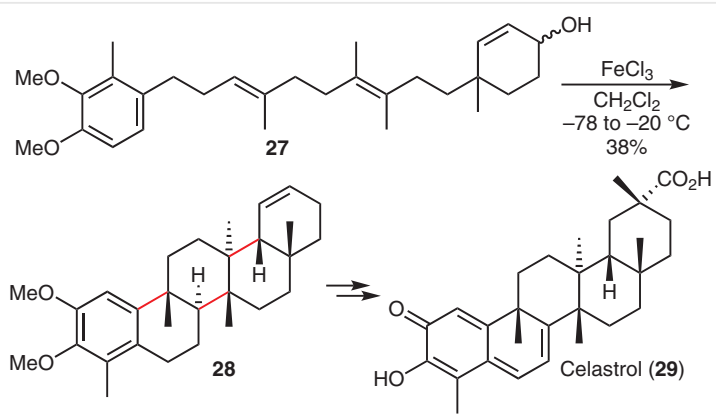

Scheme 6 Synthesis of celastrol

producing alkene $\mathbf{2 8}$ only in $15 \%$ yield. Further manipulation of alkene $\mathbf{2 8}$ was used to complete the total synthesis of celastrol (29) in 31 steps overall.

The marine natural product (-)-cyclosmenospongine (32) is a tetracyclic meroterpenoid which was synthesized by Magauer and co-workers using polyene cyclizations (Scheme 7). ${ }^{12}$ The approach featured an unprecedented stepwise non-biomimetic polyene cyclization of an aryl enol ether $\mathbf{3 0}$ catalyzed by ethylaluminum dichloride as the Lewis acid. This led to the closure of three rings with excellent control of four stereocenters on a gram scale to yield alcohol 31 (83\%) as a single diastereomer. Excellent stereoselectivity was observed due to the transition state governed by the double-bond geometry of the enol ether, thioenol ether, and epoxide. Utilizing the same strategy, (-)-5epi-aureol (35) was also synthesized via alcohol 34 (91\%), which was prepared from aryl enol ether $\mathbf{3 3 .}{ }^{10}$

Chang and co-workers reported that tin(II) triflate catalyzed the polyene cyclization of $\beta$-keto sulfones (Scheme $8)^{13}$ It was found that this Lewis acid could catalyze the cy- 


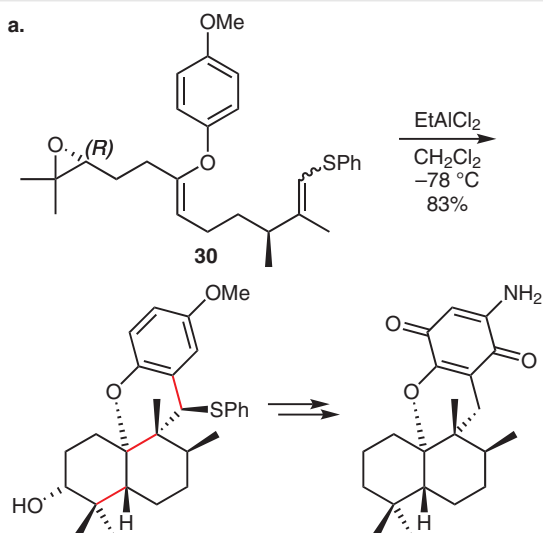

31 (-)-Cyclosmenospongine (32)

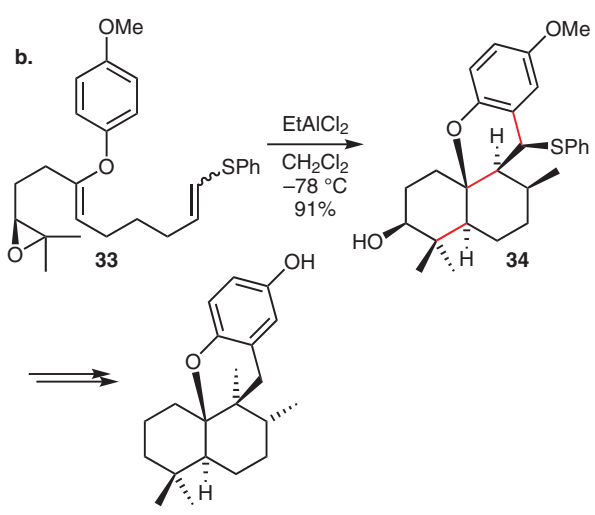

(-)-5-epi-Aureol (35)

Scheme 7 Synthesis of (-)-cyclosmenospongine and (-)-5-epi-aureol
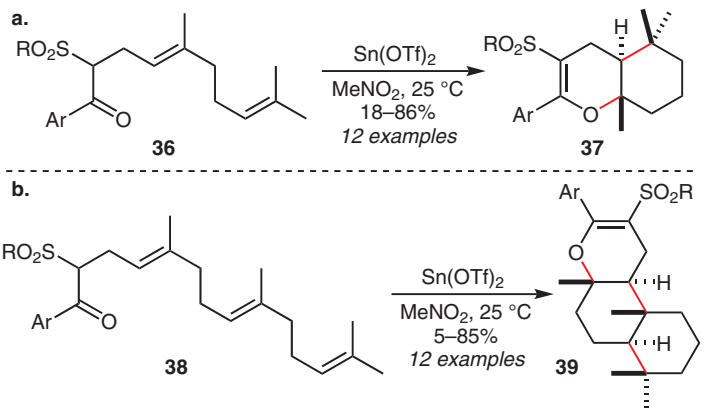

Scheme 8 Bi- and tricyclization reactions of $\beta$-keto sulfones

clization of $\beta$-keto sulfones $\mathbf{3 6}$ and $\mathbf{3 8}$, which were derived from geranyl bromide and farnesyl bromide, to give bi- and tricyclic sulfonyl dihydropyrans $\mathbf{3 7}$ and $\mathbf{3 9}$, respectively, as ambrox analogues via six-membered chairlike conformations.

Electrophilic polyene cyclization of zerumbone (40), an isoprenoid, via carbonyl activation was reported by Appendino and co-workers (Scheme 9). ${ }^{14}$ Carbonyl activation of zerumbone (40) with electrophilic reagents resulted in a Nazarov-type polyene cyclization, leading to the formation of a variety of cyclized products after intramolecular rearrangement. Zerumbone (40) is very stable towards mineral acids, but undergoes intramolecular cyclizations upon treatment with a variety of Lewis acids. Reaction of zerumbone (40) with aluminum trichloride resulted in the formation of the racemic tricyclic enone $\mathbf{4 1}$ (44\%), featuring a $5 / 5 / 7$ ring system as a single product along with recovered starting material. On the other hand, bicyclic dienone $\mathbf{4 2}$ (18\%) was formed via tin(IV) chloride mediated cyclization. Furthermore, upon treatment of zerumbone (40) with boron tribromide, a mixture of isomeric hydrocarbons $\mathbf{4 3}$ (6\%) and $44(10 \%)$ were formed following a series of rearrangements reactions.

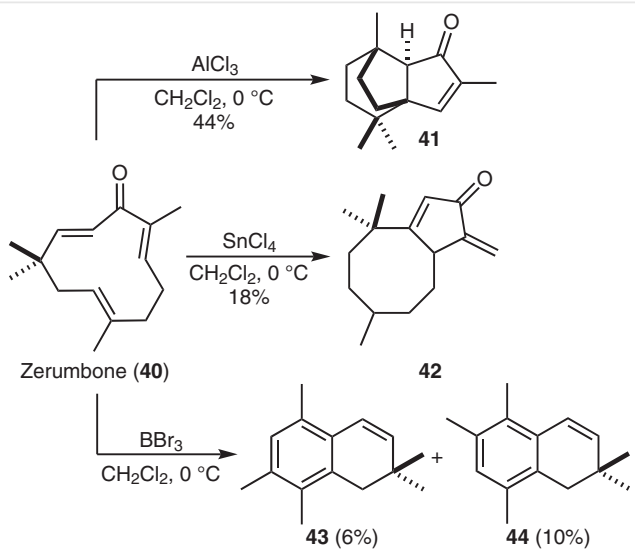

Scheme 9 Polyene cyclizations of zerumbone

McErlean and co-workers reported the first total synthesis of 5-epi-taiwaniaquinone $\mathrm{G}(\mathbf{4 8})$ via Lewis acid catalyzed polyene cyclization (Scheme 10). ${ }^{15}$ Taiwaniaquinone $G(49)$ is a diterpene containing a 6/5/6 trans-fused ring system. It was envisioned that Lewis acid mediated polyene cyclization of geranylbenzene $\mathbf{4 5}$ would lead to the formation of the desired trans-fused 5/6 ring system. Surprising-
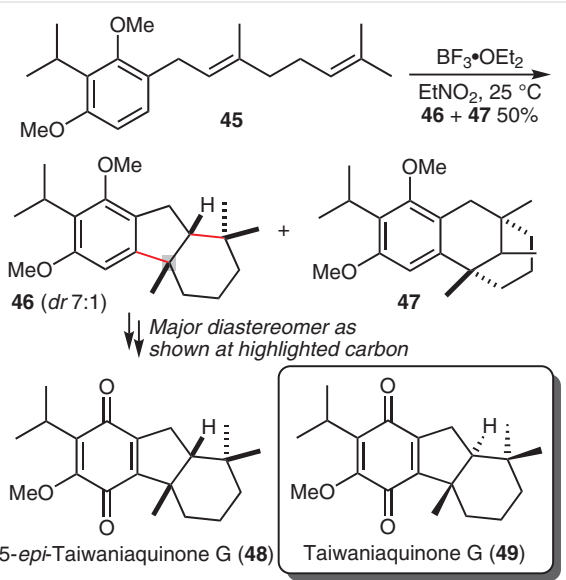

Scheme 10 Synthesis of ( \pm )-5-epi-taiwaniaquinone G 
ly, boron trifluoride-diethyl ether complex induced cationic cyclization led to the formation of a mixture of tricyclic products 46 and 47 in $50 \%$ combined yield, in which the cisfused 5/6 ring system of tricyclic intermediate $\mathbf{4 6}$ was the major diastereomer ( $\mathrm{dr} 7: 1$ ). The observed diastereoselectivity was further investigated by a computational study incorporating a conductor-like polarizable continuum model, which led to the conclusion that the observed selectivity was due to steric interactions that destabilized the transition state leading to the trans-configured diastereomer.

(-)-Parvifloron F (52) was found to be a valuable abietane diterpene that exhibits multiple biological activities such as antibacterial and antiproliferative activity against several human tumor cell lines. ${ }^{16}$ Nakagawa-Goto and coworkers achieved the first total synthesis of (-)-parvifloron $\mathrm{F}(\mathbf{5 2})$, which utilized tin(IV) chloride mediated polyene cyclization of epoxide $\mathbf{5 0}$ to give alcohol $\mathbf{5 1}$ (60\%), furnishing the tricyclic core of the natural product (Scheme 11).<smiles>COc1cc(CCC2=C(C)CCC3OC23C)cc(C(C)C)c1OC</smiles>

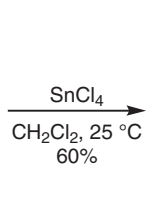<smiles>COc1c(C(C)C)cc2c(c1OC)[C@]1(C)CC[C@@H](O)C(C)(C)[C@H]1C[C@@H]2C</smiles><smiles>C=C=C</smiles><smiles></smiles>

Scheme 11 Synthesis of (-)-parvifloron $F$

\subsection{Brønsted Acid Mediated Polyene Cyclizations}

Polyfunctionalized benzhydryl alcohols were found to be able to undergo $S_{N} 1$-type ionization thereby triggering polyene cyclization promoted by hot water and 1,1,1,3,3,3hexafluoropropan-2-ol (HFIP) as a mildly acidic catalyst (Scheme 12). ${ }^{17}$ Stable carbocations, generated from such electron-rich benzylic alcohols by water, react with carbon, sulfur, and nitrogen nucleophiles in aqueous conditions. Qu and co-workers discovered that allylic alcohol $\mathbf{5 3}$ underwent polyene cyclization in a 3:1 mixture of refluxing water and HFIP to form octahydrophenanthrene product $\mathbf{5 4}$ (80\%, dr 24:1:1:0.35) with excellent diastereoselectivity. Equivalent tricyclization of allylic alcohol $\mathbf{5 5}$ gave tetracycle $\mathbf{5 6}(51 \%, \mathrm{dr} 3: 1)$ in higher yield and with better diastereoselectivity when the reaction was performed in neat HFIP.

Further studies by the Qu group discovered that HFIP could act as a Brønsted acid $\left(\mathrm{p} K_{\mathrm{a}}=9.3\right)$ catalyst to promote epoxide initiated cationic $\pi$-cyclizations (Scheme 13)..$^{18}$ The addition of tetraphenylphosphonium tetrafluoroborate enhanced the rate of reaction presumably due to trace amounts of hydrogen fluoride generated by tetrafluorobo-
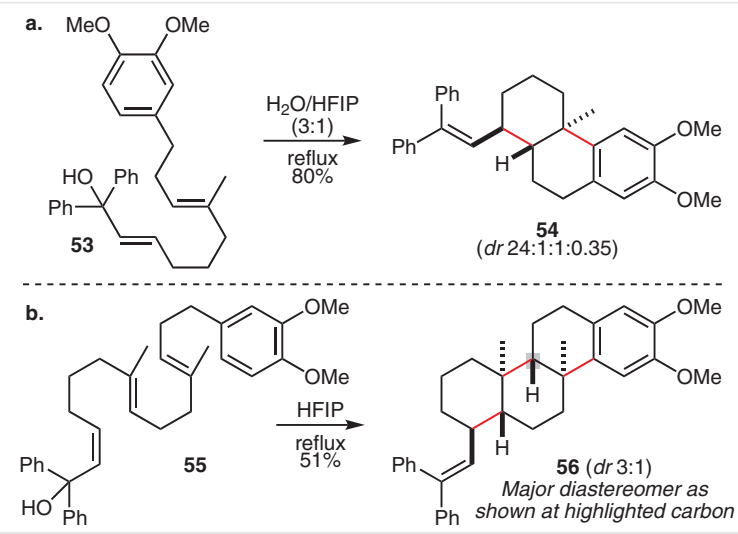

Scheme 12 Di- and tricyclizations promoted by HFIP/hot water

rate anion solvolysis in HFIP. Therefore, the reaction medium acted as both Brønsted acid and solvent to promote epoxides 57, 59, and 61 to undergo di-, tri-, and tetracyclizations rapidly to yield polycyclic compounds 58,60 , and $\mathbf{6 2}$, respectively.
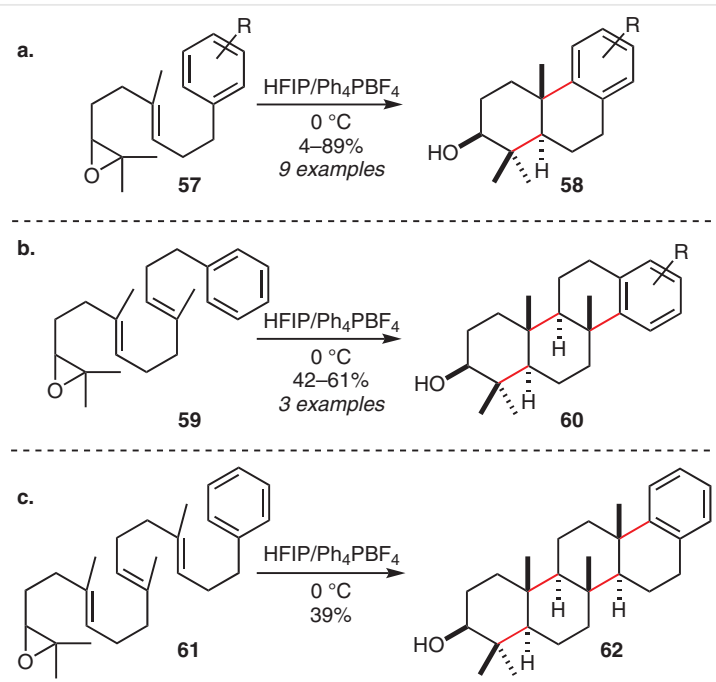

Scheme $13 \mathrm{HFIP} / \mathrm{Ph}_{4} \mathrm{PBF}_{4}$-promoted polyene cyclizations

Following the pioneering work on Lewis acid assisted chiral Brønsted acid (chiral LBA) mediated polyene cyclization from the Yamamoto and Corey groups, ${ }^{19}$ Chein and coworkers reported an enantioselective polyene cyclization of 2-(homogeranyl)anisole 63 with the BINOL derivative 67 and tin(IV) chloride en route to galanal A (65) and B (66) (Scheme 14). ${ }^{20}$ Enantioselective protonation with the complex tin(IV) chloride.67 provided a mixture of tricyclic compound 64 along with monocyclized products as the major components. Subsequent exposure of the mixture to tin(IV) chloride and trifluoroacetic acid provided octahydrophenanthrene $\mathbf{6 4}$ (86\% over 2 steps, $57 \%$ ee) as the key intermediate, which was converted into galanal A (65) and B (66). 

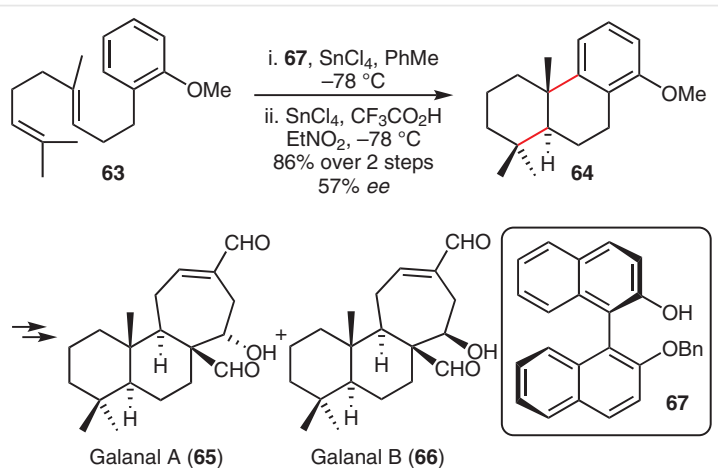

Scheme 14 Synthesis of galanal A and B

Meroterpenoid berkeleyone A (70), which is produced by a fungus Penicillium rubrum, inhibits caspase-1, a protein associated with Alzheimer's and Parkinson's diseases. Newhouse and co-workers reported a 13-step total synthesis of ( \pm )-berkeleyone A (70) utilizing a Brønsted acid mediated epoxy-diene polyene cyclization as the key step to form the tricyclic framework (Scheme 15). ${ }^{21}$ While most epoxide-initiated polyene cyclizations are activated with Lewis acids, the desired polyene cyclization of epoxide $\mathbf{6 8}$ required a Brønsted acid to facilitate the carbon-based nucleophilic attack of the $\beta$-keto ester moiety to terminate the cyclization. After extensive screening of Lewis and Brønsted acids promotors for the polyene cyclization of epoxide $\mathbf{6 8}$ to alcohol 69, it was found that the yellow ether solvated complex of $\mathrm{HFeCl}_{4}$, prepared in situ by reaction of iron(III) chloride in $\mathrm{CH}_{2} \mathrm{Cl}_{2}$ with anhydrous hydrogen chloride in diethyl ether, was the best promoter for the desired polyene cyclization to form alcohol $\mathbf{6 9}$ (39\%). This led to the formation of three $\mathrm{C}-\mathrm{C}$ bonds and generated six stereogenic centers to furnish the majority of the berkeleyone scaffold. Control experiments showed that the active Brønsted acid $\left[\mathrm{FeCl}_{4}\right]^{-}$anion was superior to either iron(III) chloride or anhydrous hydrogen chloride alone.
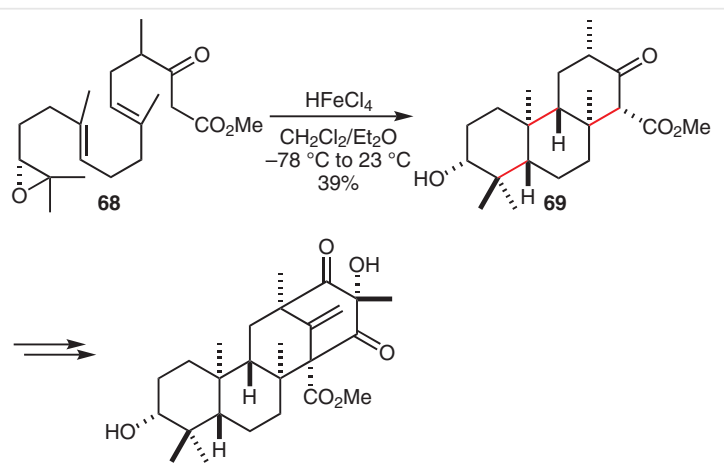

( \pm )-Berkeleyone A (70)

Scheme 15 Synthesis of ( \pm )-berkeleyone A
Zhao and co-workers developed a chiral Brønsted acid $\mathrm{N}$-phosphoramide from BINOL that catalyzed enantioselective polyene cyclization via protonation (Scheme 16). ${ }^{22}$ This methodology focused on the protonation of an imine to produce an iminium ion as initiator for the polyene cyclization. It was found that $\mathrm{N}$-phosphoramidate $\mathbf{7 6}$ provided optimal enantioselectivity and addition of magnesium thiosulfate hexahydrate improved the reaction rate with enhanced enantioselectivity at $-60{ }^{\circ} \mathrm{C}$. A broad range of substituted arenes are compatible as terminating nucleophiles under the reaction conditions. Furthermore, its application was showcased in the first total synthesis of (-)-ferruginol (75), the enantiomer of diterpene natural product (+)-ferruginol which has antifungal, antimicrobial, antitumor, and anti-inflammatory activities. The $\mathrm{N}$-phosphoramide $\mathbf{7 6}$ catalyzed enantioselective protonation of the resulting imine derived from aldehyde $\mathbf{7 3}$ with 4-toluenesulfonamide, which was utilized as the key step to induce polyene cyclization, forming the dicyclized intermediate $\mathbf{7 4}$ for the total synthesis of (-)-ferruginol (75).
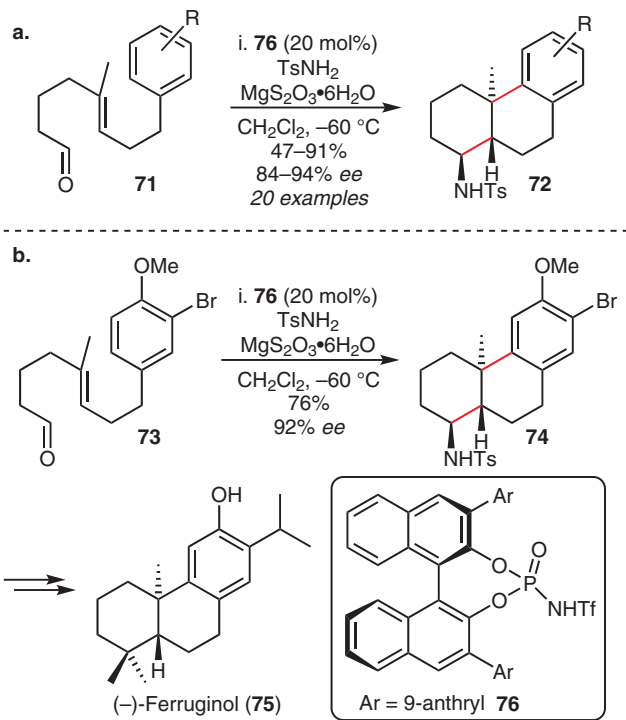

Scheme 16 Synthesis of (-)-ferruginol

A new protocol for the synthesis of cyclohexanones developed by Rodríguez and co-workers, ${ }^{23}$ was extended to the cationic polyene cyclization of polyenynes (Scheme 17). Tetrafluoroboric acid acts as the promotor for the cyclization, employing HFIP as the solvent. The reaction was initiated by alkene protonation and terminated by trapping the final alkenyl cation with water. Three different polyenynes derived from geraniol 77, nerol 79, and farnesol 81 were cyclized to provide ketones $\mathbf{7 8}(82 \%, \mathrm{dr}>20: 1), \mathbf{8 0}(80 \%, \mathrm{dr}$ $3: 1)$, and $\mathbf{8 2}(65 \%$, dr 3:1), respectively. 
<smiles>C#CCC/C=C(/C)CCC=C(C)C</smiles>
77<smiles>C#CCC/C=C(/C)CCC=C(C)C</smiles>
79<smiles>C#CCCCC1=CCCC(CCCC(C)=CC)=C1</smiles>

81

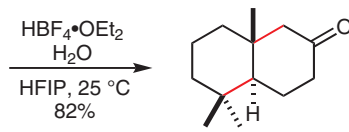
$78(d r>20: 1)$
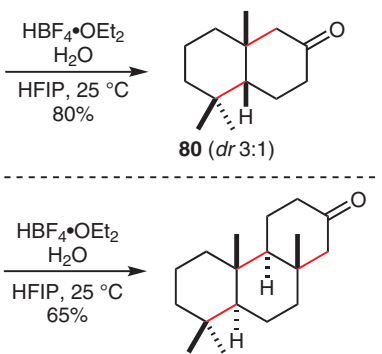

$82(d r 3: 1)$

Scheme 17 Cationic polyenyne cyclizations

Qiu and co-workers have isolated new natural meroterpenoids ( \pm )-cochlactone $\mathrm{A}(\mathbf{8 4})$ and $\mathrm{B}(\mathbf{8 5})$ that display antiinflammatory activities (Scheme 18). ${ }^{24}$ It was postulated that the possible biogenetic pathway for cochlactone $\mathrm{A}(\mathbf{8 4})$ could be from ganomycin $C$ (83) by acid-catalyzed cyclization. After optimization of the reaction conditions, it was found that exposure of ganomycin C (83) to $p$-toluenesulfonic acid resulted in polyene cyclization, thereby producing a product mixture containing $( \pm)$-cochlactone $A(\mathbf{8 4})$ and $\mathrm{B}(\mathbf{8 5})$ (42\% combined yield) in 2:1 ratio.

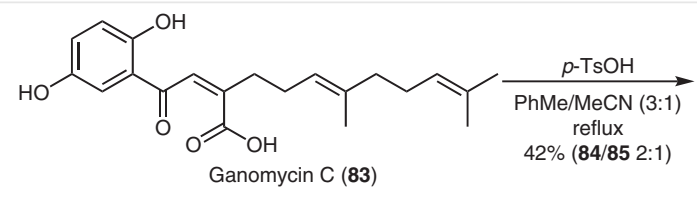<smiles>CC1(C)CCC[C@@H]2CC[C@](CC(=O)c3cc(O)ccc3O)(C1)C(=O)O2</smiles>

$( \pm)$-Cochlactone A (84)

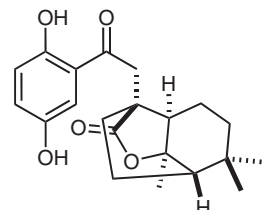

$( \pm)$-Cochlactone B (85)
Scheme 18 Synthesis of ( \pm )-cochlactone A and B

By utilizing sequential biomimetic polyketide and polyene cyclizations, the Barrett group completed a concise 6 step synthesis of (+)-hongoquercin A (89) (Scheme 19). ${ }^{7 \mathrm{~b}} \mathrm{~A}$ farnesol (86)-derived resorcylate $\mathbf{8 7}$ was protonated enantioselectivity and regioselectively at the terminal alkene to promote polyene cyclization with tin(IV) chloride.90, developed by the Yamamoto group as a Lewis acid enhanced Brønsted acid,19e thereby producing meroterpenoid $\mathbf{8 8}$ $(61 \%, 81 \%$ dr, $90 \%$ ee). Subsequent saponification of meroterpenoid $\mathbf{8 8}$ was used to complete the synthesis of $(+)-$ hongoquercin $\mathrm{A}(\mathbf{8 9})$ (75\%).
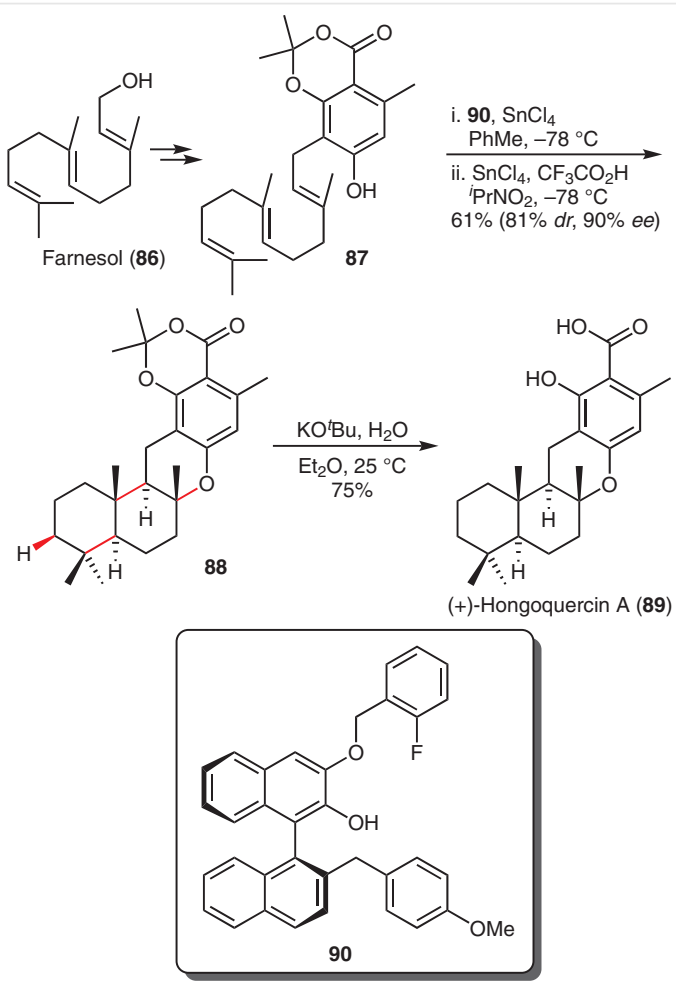

Scheme 19 Synthesis of (+)-hongoquercin A

\subsection{Halogen Electrophile Initiated Polyene Cycliza- tions}

In 2009, the Snyder group invented bromodiethylsulfonium bromopentachloroantimonate $\left(\mathrm{Et}_{2} \mathrm{SBr} \cdot \mathrm{SbCl}_{5} \mathrm{Br}\right.$, BDSB, 93), which was shown to be an efficient reagent to induce bromonium ion mediated polyene cyclizations and electrophilic aromatic substitution reactions. ${ }^{25}$ Recent findings by the Snyder group further demonstrated its ability to mediate the cyclization of alkene $\mathbf{9 0}$ to produce the spiro[5.5] undecane derivative 91 via bromonium-induced polyene cyclization accompanied by regio- and stereoselective $\alpha$-bromination of the ketone functionality (Scheme 20). ${ }^{26}$

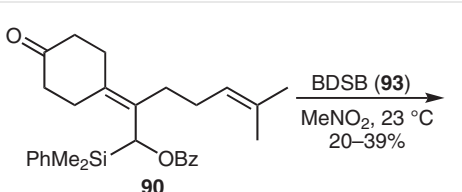<smiles>C[C@]12CC(=O)CC(CCO)(CCC1Br)C2Br</smiles>

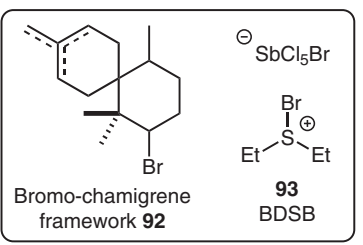

Scheme 20 Bromonium-mediated polyene cyclization for the synthesis of the chamigrene framework 
Spirocycle 91 possesses the essential framework of bromochamigrene 92, which could provide access to the chamigrene family of natural products.

The first reported catalytic enantioselective bromonium-mediated polyene cyclization was developed by the Yamamoto group (Scheme 21).27 This reaction was catalyzed by a chiral thiophosphoramidate 98 and employed 1,3-dibromo-5,5-dimethylhydantoin (DBDMH, 99) as an electrophilic bromine source. Enantioselective bromocyclization of geranylbenzenes $\mathbf{9 4}$ provided a mixture of fully and partially cyclized products. Subsequent treatment of the reaction mixture with chlorosulfonic acid promoted the final cyclization of the partially cyclized products to give bromides 95 . On the other hand, bromocyclization of geranylphenols 96 under the same conditions provided fully cyclized bromides $\mathbf{9 7}$ as single diastereomers with excellent enantioselectivities without additional treatment with chlorosulfonic acid.

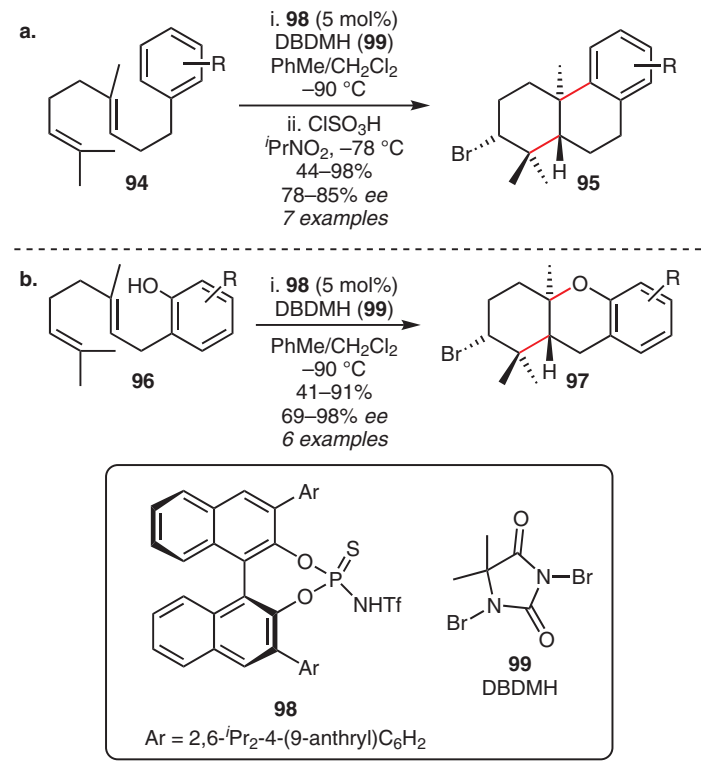

Scheme 21 Catalytic enantioselective bromonium ion mediated polyene cyclizations

Rodríguez, Fañanás, and co-workers reported an acidmediated cationic cyclization of polyenynes to form halogen-containing polycyclic compounds (Scheme 22). ${ }^{28}$ Protonation of the alkene functionality of enyne 77 by tetrafluoroboric acid induced a cationic polyene cyclization which was terminated by the alkyne group to form an intermediate alkenyl cation that reacted with a halide source. It was observed that the dienyne $\mathbf{7 7}$ cyclized to give the corresponding chloride 100 (76\%), bromide 101 (70\%), or fluoride 102 (90\%) when the halogenated solvent used in the reaction was changed to dichloromethane, dibromomethane, or hexane. While a geraniol-derived dienyne gave the trans-fused compounds 100-102 exclusively, cis-fused compound 103 was obtained diastereoselectively from ne- rol-derived dienyne 79. Furthermore, cyclization with substrate 105 containing an internal alkyne produced an indane derivative 106 (70\%) as a mixture of geometric isomers. It is important to note that bicyclic bromide $\mathbf{1 0 1}$ served as a common intermediate for the total synthesis of ( \pm )-austrodoral (107), ( \pm )-pallescensin A (108), and ( \pm )-9epi-ambrox (109).

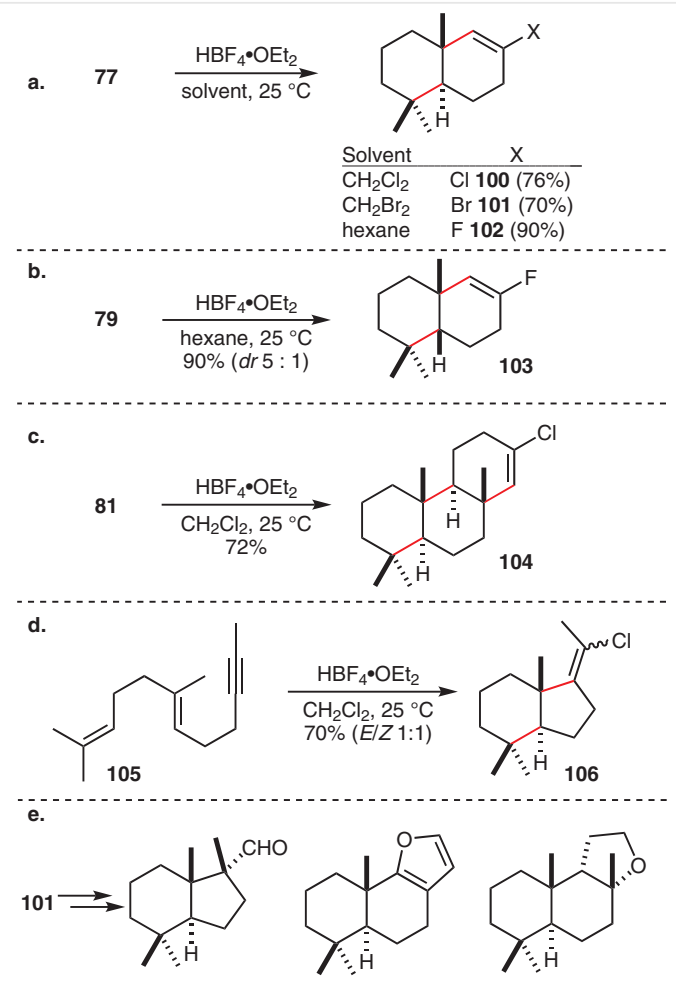

( \pm )-Austrodoral (107) $( \pm$ )-Pallescensin A (108) $( \pm$ )-9-epi-Ambrox (109)

Scheme 22 Cyclization of polyenynes

Hennecke and co-workers discovered that a stable bromonium salt 111 underwent electrophilic addition to alkenes that induced halocyclization of polyenes (Scheme 23). ${ }^{29}$ Bromonium salt $\mathbf{1 1 1}$ is a sterically demanding bromonium ion with the weakly coordinating tetrakis[3,5-

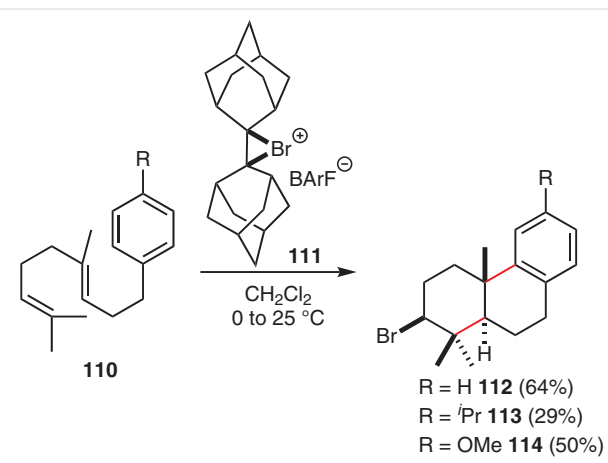

Scheme 23 Bromocyclization with a bromonium salt 
bis(trifluoromethyl)phenyl]borate (BArF-) counterion. Reaction of this salt $\mathbf{1 1 1}$ with homogeranyl arenes $\mathbf{1 1 0}$ effectively furnished fully cyclized bromides 112-114 (29-64\%).

The halocyclization of polyenes was also mediated using an electrophilic halogen source in the presence of the Lewis base morpholine with HFIP acting as the Lewis acid according to findings in 2018 by Gulder and co-workers (Scheme 24). ${ }^{30}$ Reaction of morpholine and either $N$-bromosuccinimide (NBS), $N$-iodosuccinimide (NIS), or 1,3-dichloro-5,5dimethylhydantoin (DCDMH) generates the corresponding $\mathrm{N}$-halomorpholine 116, which acts as the halogenating reagent. Homogeranyl benzene $\mathbf{1 1 5}$ was successfully converted into the corresponding fully cyclized halides 117-119 with excellent diastereoselectivities using $N$-halomorpholines 116. HFIP was identified as the best solvent for this transformation because of its Lewis acidic, highly polar, and strongly hydrogen-bond donating, but weakly nucleophilic, properties. It is essential for HFIP to activate the $\mathrm{N}$-halomorpholine 116 via hydrogen-bonding for halogenation to take place. Furthermore, HFIP could possibly prearrange the aryl-diene $\mathbf{1 1 5}$ via hydrophobic interactions to facilitate the cyclization. Lastly, the Lewis acidity of HFIP allows activation of the halonium ion intermediate to induce polyene cyclization.

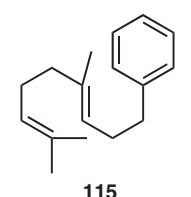

115

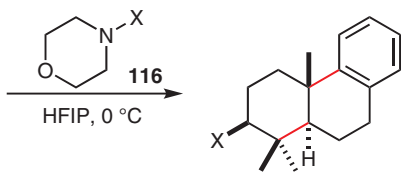

$X=\operatorname{Br} 117(78 \%, d r>19: 1)$ $X=\mid 118(78 \%, d r>19: 1)$ $\mathrm{X}=\mathrm{Cl} 119(40 \%, d r>19: 6)$

Scheme 24 Halocyclizations of polyene substrates

\subsection{Sulfur Electrophile Initiated Polyene Cycliza- tions}

The Snyder group reported three electrophilic alkyldisulfanium salts that are capable of inducing sulfur-mediated cationic polyene cyclizations (Scheme 25). ${ }^{31}$ Alkyldisulfanium salts 120-122, effectively serving as electrophilic sources of ethylsulfanium, methylsulfanium, and 3,3,3-trifluoropropylsulfanium cations, respectively, mediate the cyclization of polyene $\mathbf{1 2 3}$ to produce octahydrophenanthrenes 124-126 in modest yields (16-52\%).

Further investigations led to the development of alkyland aryldisulfanium salts $\mathbf{1 2 7}$ that could induce thiiraniummediated polyene cyclizations (Scheme 26). ${ }^{32}$ Cyclization of homogeranylbenzene $\mathbf{1 1 5}$ with alkyl and aryl sulfide electrophiles produced sulfides $\mathbf{1 2 8}$ with improved yields compared to those obtained with alkyldisulfanium salts 120122. a.
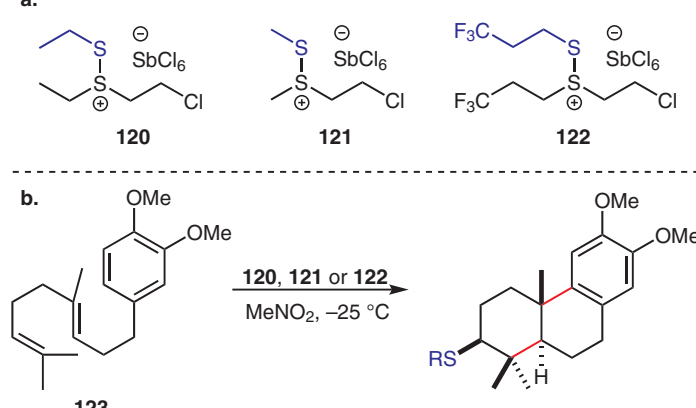

123

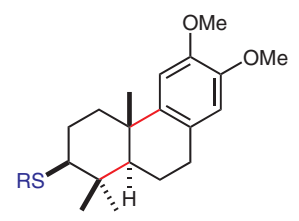

120: $R=$ Et 124 (29\%) 121: $R=$ Me $125(16 \%)$ 122: $\mathrm{R}=\mathrm{CF}_{3} \mathrm{C}_{2} \mathrm{H}_{4} 126(52 \%)$

Scheme 25 Polyene cyclizations with alkyldisulfanium salts

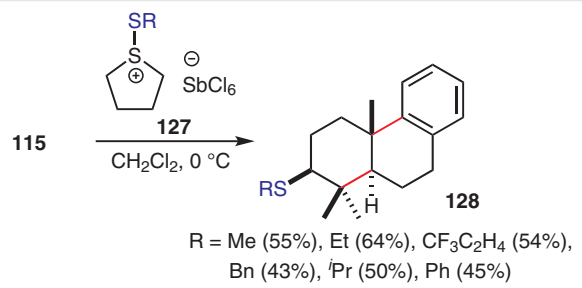

Scheme 26 Polyene cyclizations with alkyl- and aryldisulfanium salts

The first catalytic and enantioselective thiiranium ion mediated polyene cyclization was reported by Denmark and co-workers (Scheme 27). ${ }^{33}$ Homogeranylarenes 94 and ortho-geranylphenols 96 were cyclized to give the corresponding polycyclic compounds $\mathbf{1 2 9}$ and 130, respectively, via the intermediacy of an enantiomerically enriched thiiranium ion in HFIP. This reaction was catalyzed by a chiral Lewis base $\mathbf{1 3 6}$ and sulfenylating reagent 135. It is important to note that the use of HFIP as the solvent is crucial to suppress sulfenylation of the internal alkene due to solvophobic interactions between the highly polar HFIP medium and the lipophilic polyene substrate, minimizing exposure of internal alkenes. Furthermore, the acidity of HFIP is beneficial to generate the cationic active catalyst. Application of the methodology was used in enantioselective total syntheses of (+)-ferruginol (133) and (+)-hinokiol (134) from sulfide 132.

\subsection{Transition-Metal-Mediated Cationic Polyene Cyclizations}

Following the pioneering work by Gagné and co-workers on electrophilic platinum-complex-catalyzed polyene cyclization reactions, ${ }^{4 c}$ in 2014 they developed a new platinum(II) complex 143 with an $N$-heterocyclic carbene (NHC) containing pincer ligand for the synthesis of sterol-like polycyclic compounds via sequential electrophilic polyene cyclization and oxidative protonolysis (Scheme 28). ${ }^{34}$ The terminal alkene of the substrates is activated by the electro- 

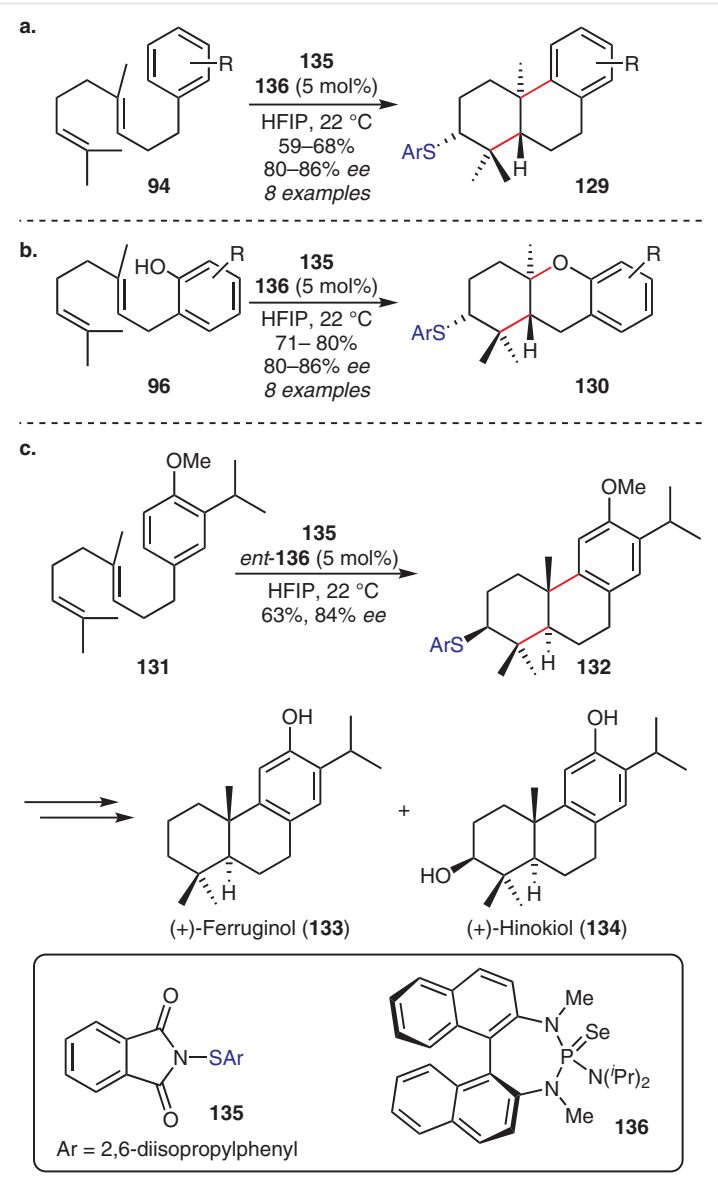

Scheme 27 Catalytic sulfenylcyclizations of polyenes

philic platinum(II) complex to initiate the polyene cyclization, followed by protodemetalation to regenerate the Pt catalyst. This methodology has a broad substrate scope and is able to induce di-, tri-, and tetracyclization reactions with a range of polyene substrates 137,139 , and 141 . Diphenylamine was added as a proton shuttle to enhance the reaction rate in some cases.

The platinum(II) catalyst $\mathbf{1 4 3}$ was also used in a study on the influence of alkene substitution on pentaene cyclizations (Scheme 29). ${ }^{35}$ Three unique analogues $(\mathbf{1 4 4}, \mathbf{1 4 6}$, and 148) of pentaenes 141, with different methyl group modification, were synthesized and treated with catalyst 143, inducing polyene cyclizations to provide the cyclized products 145,147 , and $150 / 151$. It was found that replacement of methyl groups by hydrogen did not affect the efficiency of polyene cyclization compared to that of $\mathbf{1 4 1}$ except to diminish reaction rates. Pentaenes 144 and 146 both underwent the anticipated cyclization to give alkene 145 (18\%) and 147 (54\%), respectively. On the other hand, cyclization of pentaene 148 provided a mixture of two tetracyclic compounds 150 (32\%) and 151 (20\%), which were formed from the common intermediate $\mathbf{1 4 9}$ via hydride shifts. Kinetic
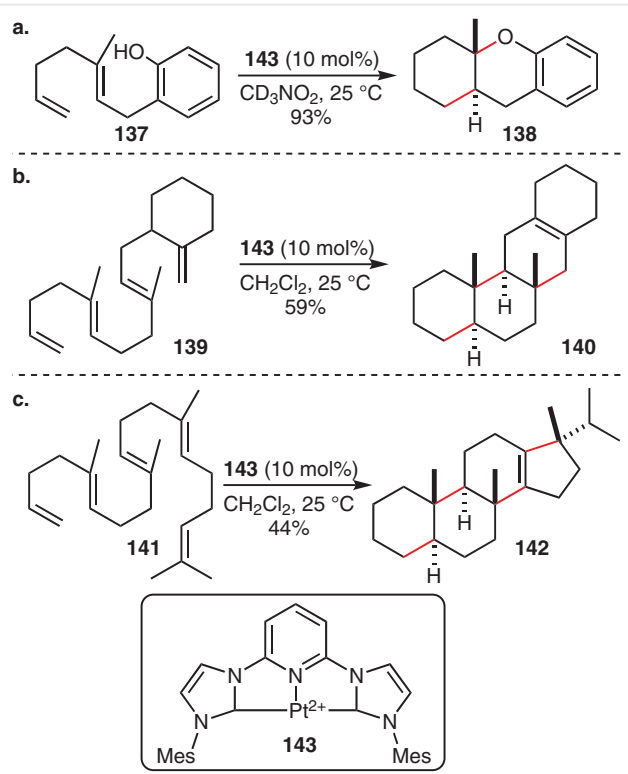

Scheme 28 Platinum(II)-meditated polyene cyclizations

studies showed that the rate of pentaene cyclization of substrates 141, 144, 146, and 148 follows the order $141>148>$ $146>144$. Computational studies suggest that pentaenes 141 and 144 form the first three rings in a concerted mechanism to generate a carbocation intermediate for further cyclizations. Pentaene $\mathbf{1 4 6}$ forms the cyclohexyl ring first, followed by concerted cyclizations to close the second and third rings. Pentaene 148 first undergoes concerted cycliza-

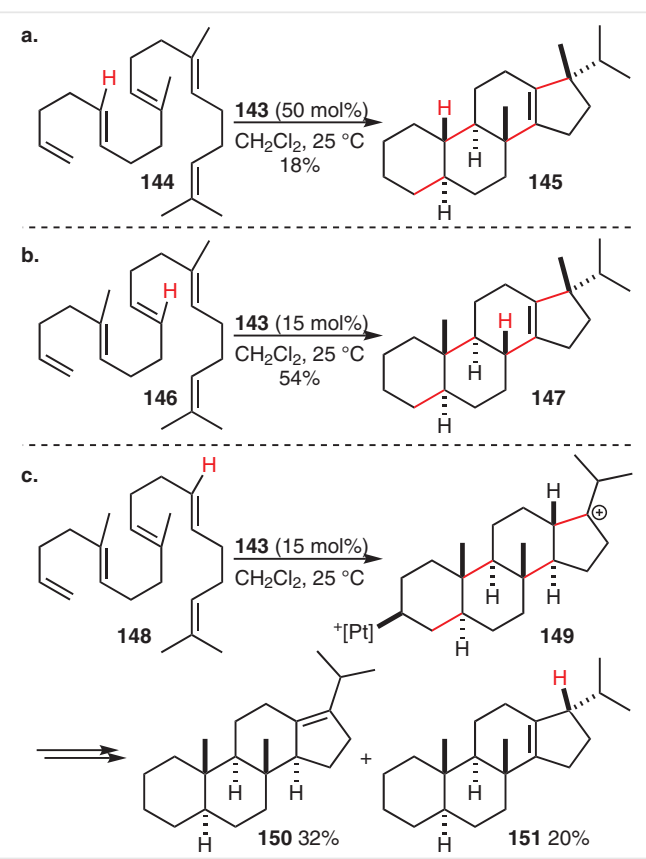

Scheme 29 Study of the influence of alkene substitution in platinum(II)-mediated polyene cyclizations 
tions to form the first two rings, followed by stepwise cyclizations to yield products $\mathbf{1 5 0}$ and $\mathbf{1 5 1}$ after different hydride shifts. Pentaenes 141, 144, and 146 generate tertiary carbocations while pentaene $\mathbf{1 4 8}$ generates a secondary carbocation after the concerted cyclizations. Furthermore, intrinsic reaction coordinate (IRC) calculations for the cyclization of pentaene 144 indicated that the reaction coordinates of the platinum(II)-catalyzed pentaene cyclizations are similar to those of the enzymatic cyclizations of squalene and oxidosqualene, suggesting that it is essentially an organometallic equivalent of a key biomimetic process.

Building upon previous research on gold(I)-catalyzed polyene cyclizations, ${ }^{36}$ a new advance was reported by Echavarren and Rong (Scheme 30). ${ }^{37}$ Activation of the enyne of polyene substrates by gold(I) triggered polyene cyclization to produce steroid-like compounds. 1,5-Enyne $\mathbf{1 5 2}$ cyclized to give alkene $\mathbf{1 5 4}$ (79\%) with the arene acting as the terminating nucleophile. Additional examples using alcohols, phenols, and heteroarenes as the terminal nucleophiles were also successfully cyclized. Furthermore, di- and tricyclization of polyenynes $\mathbf{1 5 6}$ and $\mathbf{1 6 0}$ gave the tri- and tetracyclic compounds $\mathbf{1 5 8}(90 \%)$ and $\mathbf{1 6 2}$ (59\%), respectively, under the same conditions. It was also found that bromoalkynes could be used as initiators of polyene cyclization to give cyclic bromoalkenes. For instance, the bromoalkyne
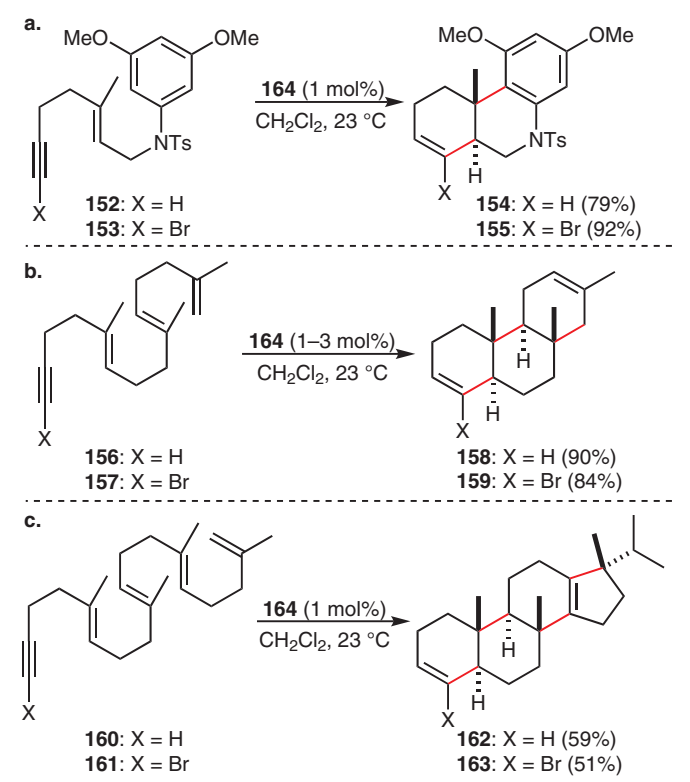
159: $\mathrm{X}=\mathrm{Br}(84 \%)$

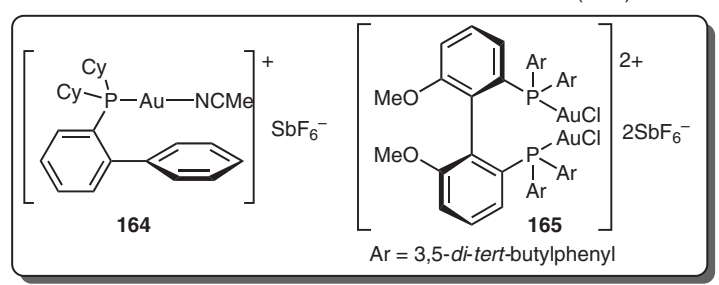

Scheme 30 Gold(I)-catalyzed polyene cyclizations of alkynes
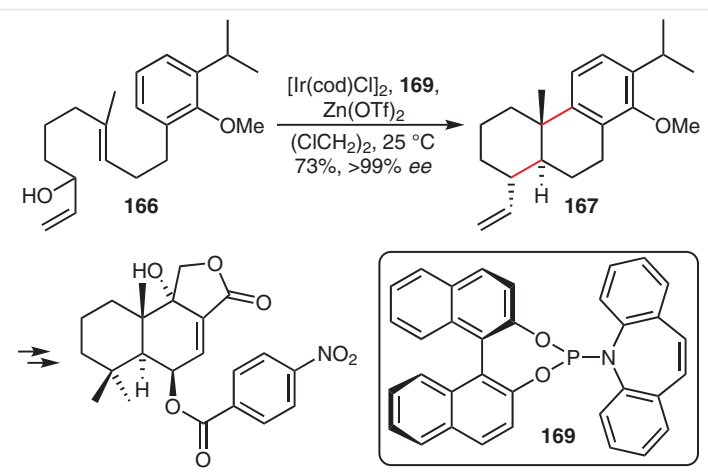

(-)-Insulicolide A (168)

Scheme 31 Synthesis of (-)-insulicolide A and related sesquiterpenoids

analogues 153,157 , and 161 were cyclized to give the corresponding synthetically useful bromoalkenes 155 (92\%), $159(84 \%)$, and 163 (51\%). The use of chiral gold(I) catalysts for the enantioselective variant of this cyclization was also investigated. It was found that moderate enantioselectivity was observed when the dinuclear gold(I) complex of BIPHEP 165 and silver(I) ditriflylimide were employed in the cyclization of 152 into 154 (85\%, 54\% ee).

(-)-Insulicolide A (168) is a nitrobenzoyloxy-substituted sesquiterpenoids with promising anticancer activity against several human cancer cell lines. The first total synthesis of (-)-insulicolide A (168) and related sesquiterpenoids was accomplished by Yang, Chen, and co-workers (Scheme 31$).{ }^{38} \mathrm{~A}$ key intermediate $\mathbf{1 6 7}$ in this synthesis was prepared from allylic alcohol $\mathbf{1 6 6}$ by an iridium-catalyzed enantioselective polyene cyclization reaction, developed by Carreira and co-workers, ${ }^{39}$ in the presence of ligand $\mathbf{1 6 9}$ to furnish the drimane core $\mathbf{1 6 7}$ (73\%, >99\% ee).

The same strategy was utilized by Li and co-workers in the total synthesis of (-)-septedine (172) and (-)-7-deoxyseptedine (173) (Scheme 32). ${ }^{40}$ The key enantiomerically pure alkene $171(61 \%,>99 \%$ ee) was prepared by the iridium-catalyzed polyene cyclization of allylic alcohol $170 \mathrm{em}-$ ploying phosphoramidite $\mathbf{1 7 4}$ as the chiral ligand.
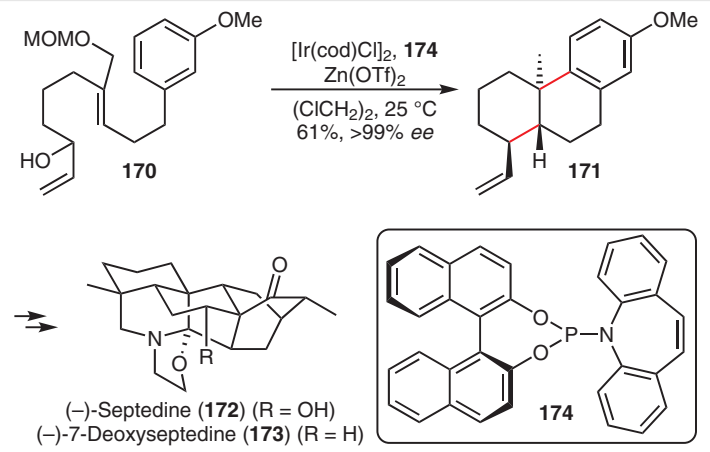

Scheme 32 Synthesis of (-)-septedine and (-)-7-deoxyseptedine 


\section{Radical Polyene Cyclizations}

\subsection{Transition-Metal-Mediated Radical Polyene Cyclizations}

While classical cationic polyene cyclizations dominate the literature on this topic, radical-mediated polyene cyclizations were proposed as early as the 1960 s by Breslow. ${ }^{41}$ The hypothesis of the biosynthetic pathway for polyene cyclizations was ambiguous, which led Breslow to the formulation of a radical approach, which was subsequently rejected. In contrast to cationic polyene cyclizations, radical processes allow a milder approach towards functionalized decalins, as radicals operate on a lower relative energy level than cationic intermediates. It should be noted that radical mediators can transform highly functionalized polyene precursors into trans-decalins with remarkable stereocontrol in a non-concerted mechanism that could be rationalized in terms of the Beckwith-Houk rules. ${ }^{42}$

In 2015, Oltra, Rosales, and co-workers reported the synthesis of ( \pm )-aureol (178), a marine natural product which exhibits cytotoxicity against A549 human non-small cell lung cancer cells and anti-influenza-A virus activity (Scheme 33). ${ }^{43}$ Application of a titanocene(III)-mediated reductive polyene cyclization of racemic epoxide 176, derived from alcohol 175, provided alcohol 177 with an exocyclic alkene with excellent relative stereochemical control. Subsequent boron trifluoride-diethyl ether catalyzed rearrangement was used in the transformation of alcohol $\mathbf{1 7 7}$ into ( \pm )-aureol (178).
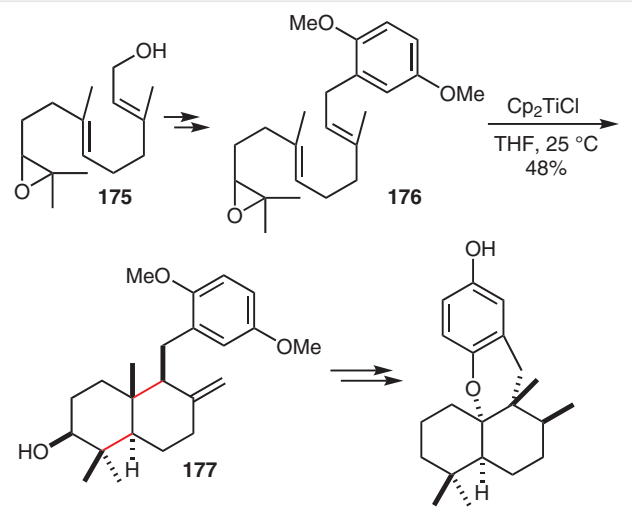

( \pm )-Aureol (178)

Scheme 33 Synthesis of $( \pm)$-aureol

The synthetic power of the titanocene(III)-mediated polyene cyclization was further demonstrated by Takahashi and co-workers in the synthesis of (-)-ent-pyripyropene A (181) (Scheme 34). ${ }^{44}$ Titanocene(III)-induced polyene cyclization of epoxide 179 gave alcohol 180 (60\%). The use of single enantiomer epoxide $\mathbf{1 7 9}$ thereby controls the outcome of the formation of 4 contiguous stereocenters. The choice of ligand in the asymmetric epoxidation allows di- versification towards natural and unnatural derivatives of the pyripyropene family. The titanocene(III)-mediated cyclization was fully automated, reproducibly allowing access to $\mathbf{1 8 0}$, a common intermediate in terpene natural product synthesis.

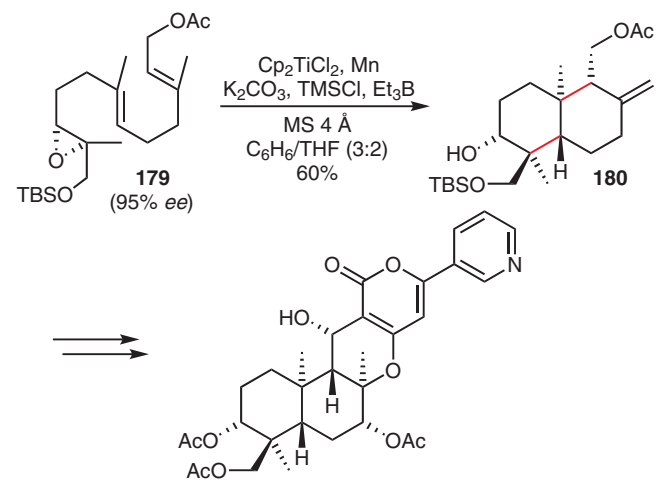

(-)-ent-Pyripyropene A (181)

Scheme 34 Synthesis of ent-pyripyropene A

Seifert and Göhl utilized a similar strategy in the synthesis of (-)-3-oxotauranin (184) and (-)-3ß-hydroxytauranin (185) (Scheme 35). ${ }^{45}$ Titanocene(III)-mediated radical polyene cyclization of epoxide $\mathbf{1 8 2}$ afforded alcohol 183, subsequent global deprotection and adjustment of oxidation state completed the synthesis of (-)-3-oxotauranin (184) and (-)-3ß-hydroxytauranin (185).

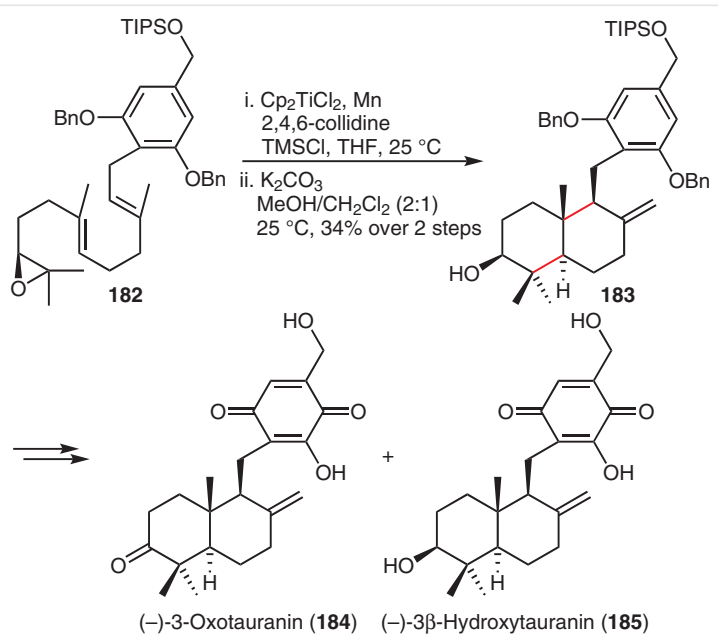

Scheme 35 Synthesis of (-)-3-oxo- and (-)-3ß-hydroxytauranin

In 2015, Trotta reported the cyclization of a geranyl $\beta$ keto ester 186 under radical conditions employing a $\mathrm{Mn}(\mathrm{III}) / \mathrm{Cu}$ (II) system to provide alcohol 187 (50\%) (Scheme 36). ${ }^{46}$ This allowed the preparation of the terpenoid transdecalin core of ( \pm )-oridamycin A (188) and B (189) with the methyl ester moiety in the axial position. 
<smiles>CC1=CCC(C(=O)O[Na])C(=O)CCC1=CCO</smiles><smiles>CCOC(=O)OC</smiles><smiles>C=C1CCC2C(CO)(CCC(=O)[C@@]2(C)OC)C1CO</smiles>
187

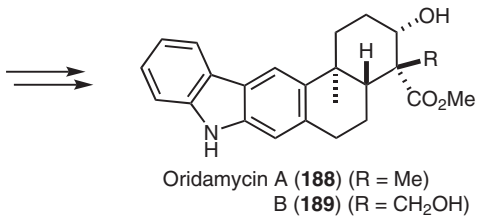

Scheme 36 Total synthesis of ( \pm )-oridamycin A and $B$

Li and co-workers reported the use of a titanocene(III)mediated polyene cyclization of epoxide $\mathbf{1 9 0}$, furnishing the trans-decalin core 191 (34\%), with the alcohol in equatorial and the methyl ester in equatorial positions (Scheme 37). ${ }^{47}$ Subsequent transformation of alcohol $\mathbf{1 9 1}$ completed the divergent synthesis of (-)-sespenine (192) and (+)-xiamycin A (193).
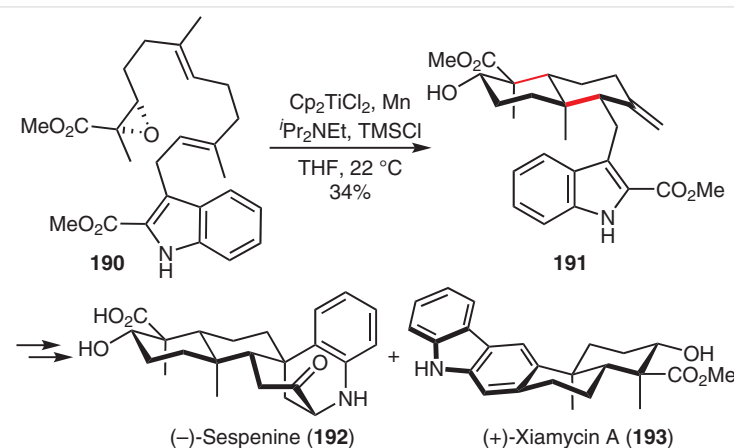

Scheme 37 Synthesis of (-)-sespenine and (+)-xiamycin A

In 2017, Shoji and co-workers reported a radical cyclization of $\beta$-keto ester 194 which was mediated by $\mathrm{Mn}(\mathrm{III}) / \mathrm{Cu}(\mathrm{II})$ to give tetracyclic ketone $\mathbf{1 9 6}(11 \%)$ and tricyclic ketone 197 , as a mixture of regioisomers (22\%) via intermediate 195 (Scheme 38). ${ }^{48}$ The functionalization arose from tuning the electron-donating or -demanding properties of the polyene scaffold to allow efficient cyclization between alternating electrophilic radicals with electron-rich trisubstituted olefins.

In 2017, Liu and co-workers reported the synthesis of (-)-hispidanin A (200), a natural product with promising anticancer properties, via a hydrogen atom transfer (HAT) mediated triene cyclization to construct the tricyclic core of (-)-hispidanin A (200) (Scheme 39). ${ }^{49}$ The use of iron(III) acetylacetonate and triphenylsilane as hydrogen source smoothly furnished tricyclic lactone $\mathbf{1 9 9}$ from alkene $\mathbf{1 9 8}$
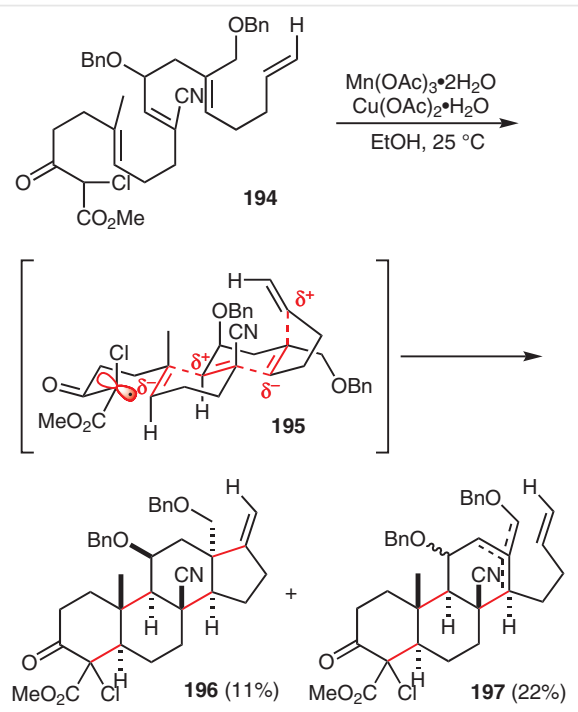

Scheme 38 Cyclization of a $\beta$-keto ester

(45\% over 2 steps) after deprotection, thereby establishing two quaternary and four contiguous stereocenters in one step. In a 2018 follow-up paper, Liu and co-workers reported further mechanistic studies, producing deuteration at the $\alpha$-position of the lactone, supporting the hypothesis that the reaction involves the formation of an enolate anion. ${ }^{50}$

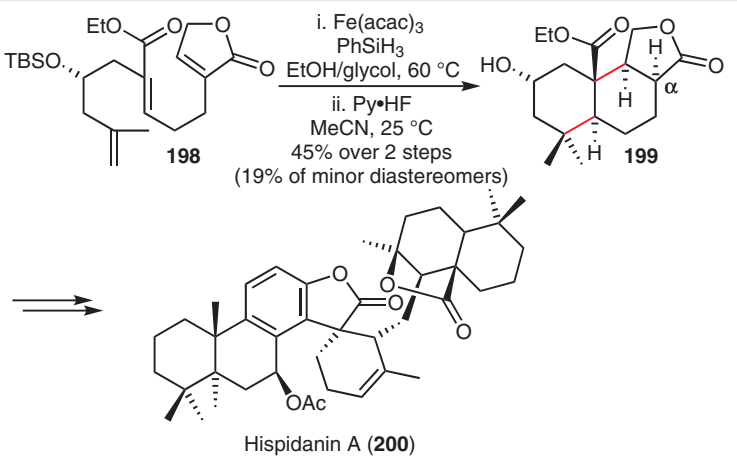

Scheme 39 Synthesis of hispidanin A

While most of these transformations are initiated by a radical generated from metal complexes, in 2018 the Baran group exploited electrochemical initiation for a radical polyene cyclization in the divergent synthesis of pyrone diterpenes sesquicillin $A(\mathbf{2 0 5})$, higginsianin $A(\mathbf{2 0 6})$, and subglutinol A (203) and B (204) (Scheme 40). ${ }^{51}$ Cyclization of $\beta$ keto ester 201 provided key intermediate alkene 202 (42\%) which was further derivatized into the different diterpene natural products. 
<smiles>C=CCOC(=O)C(C)C(=O)CCC(C)=CCCCC</smiles>
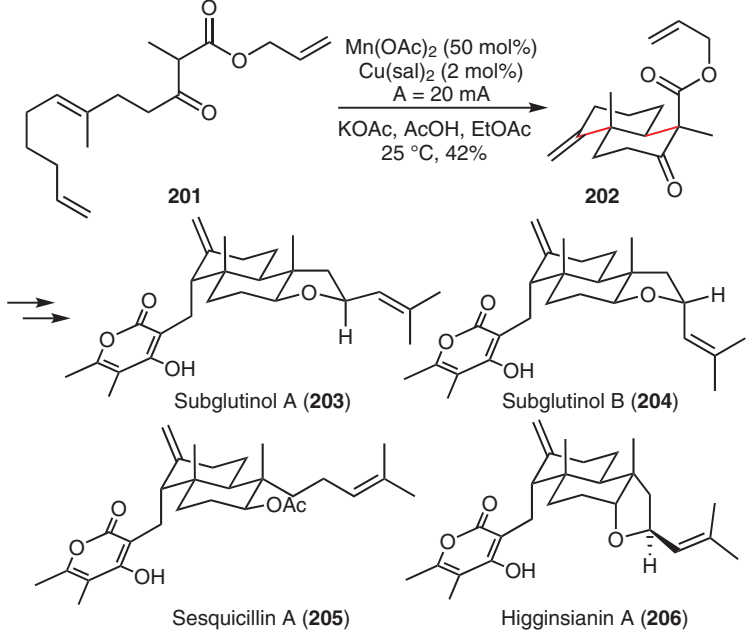

Sesquicillin A (205)

Higginsianin A (206)

Scheme 40 Synthesis of pyrone diterpenes

\subsection{Photocatalyst-Mediated Polyene Cyclizations}

Photoredox catalysis has been an ever-growing field over the last decade with numerous examples of synthetic transformations, and applications in natural product or pharmaceutical synthesis. Since the seminal work published by Demuth and co-workers on photochemically induced electron transfer polyene cyclizations, ${ }^{52}$ the utility of photocatalyst-mediated polyene cyclization has remained

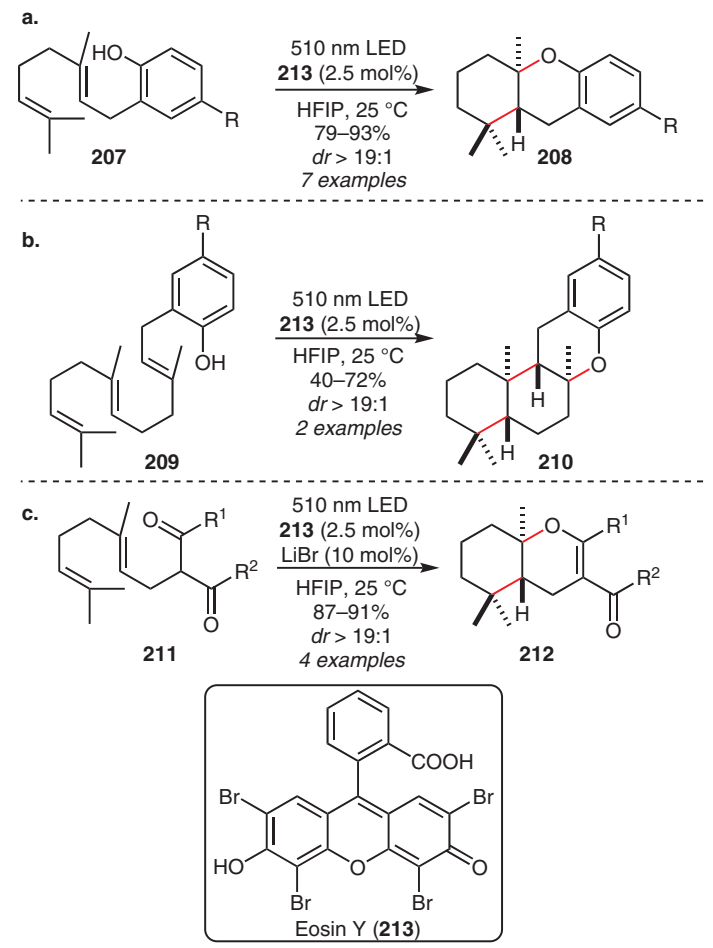

Scheme 41 Photocatalytic polyene cyclizations underexplored. One noticeable example of polyene cyclization catalyzed with eosin Y (213) was published in 2015 by Zhang, Luo, and co-workers (Scheme 41). ${ }^{53}$ The mild photoredox-catalyzed transformation tolerated various functionalization and the cyclization proceeded with excellent relative stereochemical control and diastereoselectivity for various ring systems. A selection of solvents and organic and inorganic photoredox catalysts were examined and optimal results were obtained with eosin Y in HFIP. Subsequently, an array of geranylphenols 207 and farnesylphenols 209 with various functional groups in the para position were cyclized to produce chromanes 208 and $\mathbf{2 1 0}$, respectively. 1,3-Diketones $\mathbf{2 1 1}$ also underwent photocatalyzed polyene cyclizations, thereby producing chromenes 212 with various substituents $R^{1}$ and $R^{2}$ of different electronic nature.

The synthetic utility of the photocatalyst-initiated polyene cyclization was further demonstrated in the 7-step synthesis of ( \pm )-hongoquercin A (89) (Scheme 42). ${ }^{54}$ Cyclization of phenol 214 catalyzed by eosin Y (213) provided tetracyclic compound 215 (60\% by NMR), a key intermediate with the complete carbon framework of the natural product.

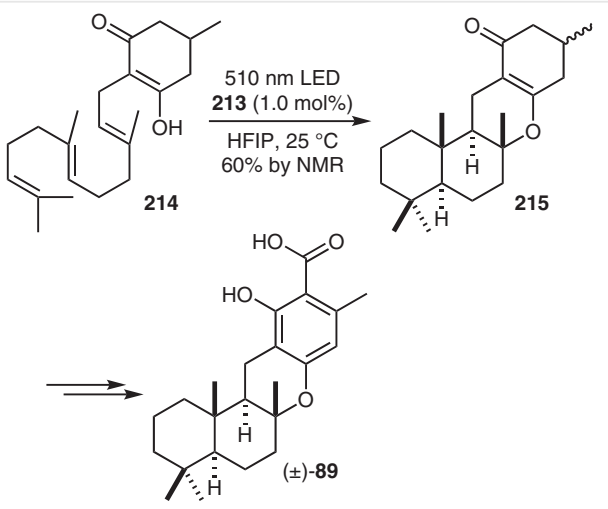

Scheme 42 Synthesis of ( \pm )-hongoquercin A

Trotta reported attempts to employ photoredox catalysts as polyene cyclization initiators during his studies on the total synthesis of xiamycin A (193)..$^{55}$ While earlier work on ( \pm )-oridamycin A (188) showed that manganese(III)-mediated cyclization gave the trans-decalin 187 with the methoxy ester in the axial position (Scheme 43); photoredox catalysts were able to convert an $\alpha$-bromo- $\beta$ keto ester 216 into the same trans-decalin compound 187.

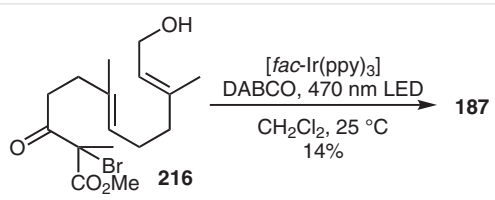

Scheme 43 Photocatalyst-mediated polyene cyclization 
When the acylated linear precursor was subjected to these conditions, it resulted in complete decomposition. Although the yields were low, the reaction proceeded at catalyst loadings as low as $0.01 \mathrm{~mol} \%$.

\section{Origin of Stereocontrol in Polyene Cycliza- tions}

Several general remarks on the observed stereoselectivity of the various methods of cationic polyene cyclization reactions can be made. The underlying principle of all the cationic cyclization reactions mentioned is that the prearranged pseudo-chair-chair-(chair) conformation such as of polyene $\mathbf{2 1 7}$ or $\mathbf{2 1 8}$ allows the efficient preparation of polycyclic compound 221 with predefined relative stereochemistry. This is based on the stereoelectronic arrangement of an olefinic double bond in close proximity to the electrophilic carbenium center in intermediate $\mathbf{2 1 9}$ and subsequently nucleophilic attack by an olefinic bond further down the chain on the intermediately formed carbenium center (Scheme 44). As such the trans-substitution of the polyene precursor sets the outcome for the observed transdecalin stereoselectivity in the concerted cationic cyclization through the given prearranged conformation according to the Stork-Eschenmoser hypothesis. ${ }^{1 a, b}$ In cases where the reactions are not proceeding in a concerted fashion, a mixture of products are formed. ${ }^{\text {a }}$

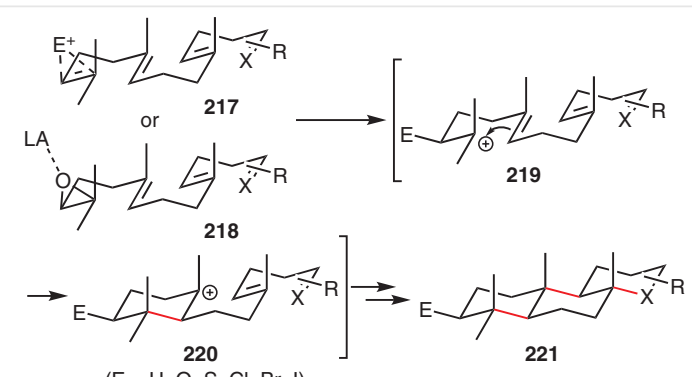

$(\mathrm{E}=\mathrm{H}, \mathrm{O}, \mathrm{S}, \mathrm{Cl}, \mathrm{Br}, \mathrm{I})$

Scheme 44 Cationic polyene cyclizations

On the other hand, the origin of stereocontrol in radical polyene cyclization reactions could be rationalized by the Beckwith-Houk rules in addition to the Stork-Eschenmoser

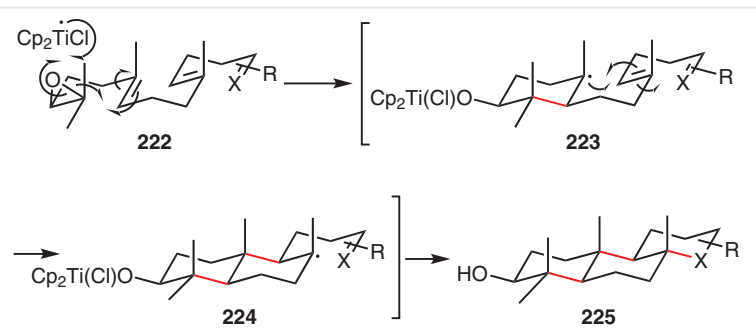

Scheme 45 Radical polyene cyclizations hypothesis (Scheme 45). ${ }^{42}$ As an illustration, titanium(III)mediated cyclization of epoxide $\mathbf{2 2 2}$ would presumably proceed in a non-concerted fashion via radical intermediates 223 and 224 and favored 6-endo-trig cyclization via a chair transition state over 5-exo-trig cyclization to produce alcohol 225 due to ring strain.

\section{Conclusion}

Inspired by nature's efficient and highly stereochemically controlled syntheses of primary and secondary metabolites via polyene cyclizations, the use of initiators such as Lewis acids, metal complexes, halonium ion transfer reagents, sulfanium ion transfer reagents, and Brønsted acids have demonstrated the synthetic utility of these bioinspired transformations with comparable selectivities and efficiencies to the enzymatic processes. Recent developments of novel polyene cyclization methodologies have significantly expanded the scope of terpene and polyene functionalization reactions, providing a wide range of unique carbon frameworks. Radical-mediated polyene cyclizations have been further investigated to achieve different modes of cyclization from the cationic pathway, allowing early and late stage functionalization of polyenes for terpene and meroterpenoid total syntheses. Photocatalyst-mediated polyene cyclizations have emerged as new alternatives, which employ milder reaction conditions as well as lower catalyst loadings. It goes without saying that future developments in electrophilic reagents and catalysts will further advance the synthetic utility of polyene cyclizations with excellent enantio- and diastereoselectivities, greatly impacting the area of terpenoid, meroterpenoid, and steroid total syntheses amongst other classes of compounds.

\section{Acknowledgment}

We thank GlaxoSmithKline for the endowment (to A.G.M.B) as well as Drs. Alfred and Isabel Bader for their additional support. We thank Dr. Sara R. Goldstein and Dr. Joshua Almond-Thynne for proofreading this review article.

\section{References}

(1) (a) Stork, G.; Burgstahler, A. W. J. Am. Chem. Soc. 1955, 77, 5068. (b) Eschenmoser, A.; Ruzicka, L.; Jeger, O.; Arigoni, D. Helv. Chim. Acta 1955, 38, 1890. (c) Eschenmoser, A.; Arigoni, D. Helv. Chim. Acta 2005, 88, 3011.

(2) (a) Johnson, W. S.; Semmelhack, M. F.; Sultanbawa, M. U. S.; Dolak, L. A. J. Am. Chem. Soc. 1968, 90, 2994. (b) Johnson, W. S. Acc. Chem. Res. 1968, 1, 1. (c) Johnson, W. S. Bioorg. Chem. 1976, $5,51$.

(3) (a) van Tamelen, E. E. Acc. Chem. Res. 1968, 1, 111. (b) van Tamelen, E. E. Acc. Chem. Res. 1975, 8, 152.

(4) For recent reviews in this area, see (a) Snyder, S. A.; Levinson, A. M. Comprehensive Organic Synthesis II; Elsevier: Oxford, 2014, 
268. (b) Li, X.-W.; Nay, B. Nat. Prod. Rep. 2014, 31, 533. (c) Felix, R. J.; Munro-Leighton, C.; Gagné, M. R. Acc. Chem. Res. 2014, 47, 2319. (d) Yoshimura, T. Tetrahedron Lett. 2014, 55, 5109. (e) Dhambri, S.; Mohammad, S.; Van Buu, O. N.; Galvani, G.; Meyer, Y.; Lannou, M.-I.; Sorin, G.; Ardisson, J. Nat. Prod. Rep. 2015, 32, 841. (f) Ardkhean, R.; Caputo, D. F. J.; Morrow, S. M.; Shi, H.; Xiong, Y.; Anderson, E. A. Chem. Soc. Rev. 2016, 45, 1557. (g) Ungarean, C. N.; Southgate, E. H.; Sarlah, D. Org. Biomol. Chem. 2016, 14, 5454. (h) Hung, K.; Hu, X.; Maimone, T. J. Nat. Prod. Rep. 2018, 35, 174. (i) Landry, M. L.; Burns, N. Z. Acc. Chem. Res. 2018, 51, 1260.

(5) (a) Xu, H.; Tang, H.; Feng, H.; Li, Y. Tetrahedron Lett. 2014, 55, 7118. (b) Xu, H.; Tang, H.; Feng, H.; Li, Y. J. Org. Chem. 2014, 79, 10110.

(6) Surendra, K.; Qiu, W.; Corey, E. J. J. Am. Chem. Soc. 2011, 133, 9724.

(7) (a) Barrett, T. N.; Barrett, A. G. M. J. Am. Chem. Soc. 2014, 136, 17013. (b) Ma, T.-K.; Elliott, D. C.; Reid, S.; White, A. J. P.; Parsons, P. J.; Barrett, A. G. M. J. Org. Chem. 2018, 83, 13276.

(8) Rosen, B. R.; Werner, E. W.; O’Brien, A. G.; Baran, P. S. J. Am. Chem. Soc. 2014, 136, 5571.

(9) Suzuki, K.; Yamakoshi, H.; Nakamura, S. Chem. Eur. J. 2015, 21, 17605.

(10) Rajendar, G.; Corey, E. J. J. Am. Chem. Soc. 2015, 137, 5837.

(11) Camelio, A. M.; Johnson, T. C.; Siegel, D. J. Am. Chem. Soc. 2015, $137,11864$.

(12) (a) Speck, K.; Wildermuth, R.; Magauer, T. Angew. Chem. Int. Ed. 2016, 55, 14131. (b) Speck, K.; Magauer, T. Chem. Eur. J. 2017, 23, 1157.

(13) Chan, C.-K.; Chen, Y.-H.; Chang, M.-Y. Tetrahedron 2016, 72, 5121.

(14) Minassi, A.; Pollastro, F.; Chianese, G.; Caprioglio, D.; Taglialatela-Scafati, O.; Appendino, G. Angew. Chem. Int. Ed. 2017, 56, 7935.

(15) Graham, M.; Baker, R. W.; McErlean, C. S. P. Eur. J. Org. Chem. 2017, 908.

(16) Saito, Y.; Goto, M.; Nakagawa-Goto, K. Org. Lett. 2018, 20, 628.

(17) Zhang, F.-Z.; Tian, Y.; Li, G.-X.; Qu, J.J. Org. Chem. 2015, 80, 1107.

(18) Tian, Y.; Xu, X.; Zhang, L.; Qu, J. Org. Lett. 2016, 18, 268.

(19) (a) Ishihara, K.; Nakamura, S.; Yamamoto, H. J. Am. Chem. Soc. 1999, 121, 4906. (b) Nakamura, S.; Ishihara, K.; Yamamoto, H. J. Am. Chem. Soc. 2000, 122, 8131. (c) Ishihara, K.; Ishibashi, H.; Yamamoto, H. J. Am. Chem. Soc. 2001, 123, 1505. (d) Ishihara, K.; Ishibashi, H.; Yamamoto, H. J. Am. Chem. Soc. 2002, 124, 3647. (e) Ishibashi, H.; Ishihara, K.; Yamamoto, H. J. Am. Chem. Soc. 2004, 126, 11122. (f) Surendra, K.; Corey, E. J. J. Am. Chem. Soc. 2012, 134, 11992. (g) Surendra, K.; Rajendar, G.; Corey, E. J. J. Am. Chem. Soc. 2014, 136, 642.

(20) Lin, S.-C.; Chein, R.-J. J. Org. Chem. 2017, 82, 1575.

(21) Elkin, M.; Szewczyk, S. M.; Scruse, A. C.; Newhouse, T. R. J. Am. Chem. Soc. 2017, 139, 1790.

(22) Fan, L.; Han, C.; Li, X.; Yao, J.; Wang, Z.; Yao, C.; Chen, W.; Wang, T.; Zhao, J. Angew. Chem. Int. Ed. 2018, 57, 2115.

(23) Alonso, P.; Fontaneda, R.; Pardo, P.; Fañanás, F. J.; Rodríguez, F. Org. Lett. 2018, 20, 1659.

(24) Peng, X.-R.; Lu, S.-Y.; Shao, L.-D.; Zhou, L.; Qiu, M.-H. J. Org. Chem. 2018, 83, 5516.

(25) (a) Snyder, S. A.; Treitler, D. S. Angew. Chem. Int. Ed. 2009, 48, 7899. (b) Snyder, S. A.; Treitler, D. S.; Brucks, A. P. J. Am. Chem. Soc. 2010, 132, 14303.

(26) Shen, M.; Kretschmer, M.; Brill, Z. G.; Snyder, S. A. Org. Lett. 2016, 18, 5018.
(27) Samanta, R. C.; Yamamoto, H. J. Am. Chem. Soc. 2017, 139, 1460.

(28) Alonso, P.; Pardo, P.; Fontaneda, R.; Fañanás, F. J.; Rodríguez, F. Chem. Eur. J. 2017, 23, 13158.

(29) Ascheberg, C.; Bock, J.; Buß, F.; Mück-Lichtenfeld, C.; Daniliuc, C. G.; Bergander, K.; Dielmann, F.; Hennecke, U. Chem. Eur. J. 2017, 23, 11578.

(30) Arnold, A. M.; Pöthig, A.; Drees, M.; Gulder, T. J. Am. Chem. Soc. 2018, 140, 4344.

(31) Schevenels, F. T.; Shen, M.; Snyder, S. A. Org. Lett. 2017, $19,2$.

(32) Cole, C.; Chi, H.; DeBacker, K.; Snyder, S. Synthesis 2018, 50, A-H.

(33) Tao, Z.; Robb, K. A.; Zhao, K.; Denmark, S. E. J. Am. Chem. Soc. 2018, 140, 3569.

(34) Geier, M. J.; Gagné, M. R. J. Am. Chem. Soc. 2014, 136, 3032.

(35) McCulley, C. H.; Geier, M. J.; Hudson, B. M.; Gagné, M. R.; Tantillo, D. J. J. Am. Chem. Soc. 2017, 139, 11158.

(36) (a) Toullec, P. Y.; Blarre, T.; Michelet, V. Org. Lett. 2009, 11, 2888. (b) Sethofer, S. G.; Mayer, T.; Toste, F. D. J. Am. Chem. Soc. 2010, 132, 8276. (c) Pradal, A.; Chen, Q.; Faudot dit Bel, P.; Toullec, P.; Michelet, V. Synlett 2012, 2012, 74.

(37) Rong, Z.; Echavarren, A. M. Org. Biomol. Chem. 2017, 15, 2163.

(38) Lai, Y.; Zhang, N.; Zhang, Y.; Chen, J.-H.; Yang, Z. Org. Lett. 2018, 20, 4298.

(39) Schafroth, M. A.; Sarlah, D.; Krautwald, S.; Carreira, E. M. J. Am. Chem. Soc. 2012, 134, 20276.

(40) Zhou, S.; Guo, R.; Yang, P.; Li, A. J. Am. Chem. Soc. 2018, 140, 9025.

(41) (a) Breslow, R.; Barrett, E.; Mohacsi, E. Tetrahedron Lett. 1962, 3 , 1207. (b) Breslow, R.; Olin, S. S.; Groves, J. T. Tetrahedron Lett. 1968, 9, 1837.

(42) Curran, D. P.; Porter, N. A.; Giese, B. Stereochemistry of Radical Reactions; VCH: Weinheim, 1995

(43) Rosales, A.; Muñoz-Bascón, J.; Roldan-Molina, E.; Rivas-Bascón, N.; Padial, N. M.; Rodríguez-Maecker, R.; Rodríguez-García, I.; Oltra, J. E. J. Org. Chem. 2015, 80, 1866.

(44) Fuse, S.; Ikebe, A.; Oosumi, K.; Karasawa, T.; Matsumura, K.; Izumikawa, M.; Johmoto, K.; Uekusa, H.; Shin-ya, K.; Doi, T.; Takahashi, T. Chem.-Eur. J. 2015, 21, 9454.

(45) Göhl, M.; Seifert, K. Eur. J. Org. Chem. 2015, 6249.

(46) Trotta, A. H. Org. Lett. 2015, 17, 3358.

(47) Sun, Y.; Meng, Z.; Chen, P.; Zhang, D.; Baunach, M.; Hertweck, C.; Li, A. Org. Chem. Front. 2016, 3, 368.

(48) Furuta, M.; Hanaya, K.; Sugai, T.; Shoji, M. Tetrahedron 2017, 73, 2316.

(49) Deng, H.; Cao, W.; Liu, R.; Zhang, Y.; Liu, B. Angew. Chem. Int. Ed. 2017, 56, 5849.

(50) Cao, W.; Deng, H.; Sun, Y.; Liu, B.; Qin, S. Chem. Eur. J. 2018, 24, 9120.

(51) Merchant, R. R.; Oberg, K. M.; Lin, Y.; Novak, A. J. E.; Felding, J.; Baran, P. S. J. Am. Chem. Soc. 2018, 140, 7462.

(52) (a) Hoffmann, U.; Gao, Y.; Pandey, B.; Klinge, S.; Warzecha, K.D.; Krueger, C.; Roth, H. D.; Demuth, M. J. Am. Chem. Soc. 1993, 115, 10358. (b) Heinemann, C.; Demuth, M. J. Am. Chem. Soc. 1997, 119, 1129. (c) Heinemann, C.; Demuth, M. J. Am. Chem. Soc. 1999, 121, 4894. (d) Goeller, F.; Heinemann, C.; Demuth, M. Synthesis 2001, 1114. (e) Rosales, V.; Zambrano, J.; Demuth, M. Eur. J. Org. Chem. 2004, 1798. (f) Ozser, M. E.; Icil, H.; Makhynya, Y.; Demuth, M. Eur. J. Org. Chem. 2004, 3686.

(53) Yang, Z.; Li, H.; Zhang, L.; Zhang, M.-T.; Cheng, J.-P.; Luo, S. Chem. Eur. J. 2015, 21, 14723.

(54) Yang, Z.; Li, S.; Luo, S. Acta Chim. Sin. 2017, 75, 351.

(55) Trotta, A. H. J. Org. Chem. 2017, 82, 13500. 